\title{
¿Remote Influence of the Interannual Variability of the Australian Summer Monsoon on Wintertime Climate in East Asia and the Western North Pacific 0
}

\author{
ShiOn SeKizAwa, ${ }^{\mathrm{a}}$ Hisashi NaKAmura, ${ }^{\mathrm{a}}$ AND Yu Kosaka ${ }^{\mathrm{a}}$ \\ ${ }^{\text {a }}$ Research Center for Advanced Science and Technology, The University of Tokyo, Tokyo, Japan
}

(Manuscript received 13 March 2021, in final form 7 September 2021)

\begin{abstract}
Anomalous convective activity in the tropics forced by sea surface temperature (SST) variability exerts significant remote influence that provides a basis for seasonal prediction in the extratropics. In austral summer, convective activity exhibits pronounced interannual variability over northern Australia (NAUS), which is, however, unlikely to be forced by SST anomalies; rather, it is essentially a manifestation of internal variability of the Australian summer monsoon (AUSM) system. Based on observational data, the present study reveals its significant remote impacts on the wintertime climate in East Asia and the western North Pacific. The anomalous AUSM excites the western Pacific (WP) pattern, as confirmed through an atmospheric general circulation model experiment. Through this cross-equatorial teleconnection, the enhanced AUSM leads to the strengthening of the East Asian winter monsoon with a colder winter over the Korean Peninsula and western Japan and reduced precipitation over southern China. The Okhotsk sea ice extent decreases under warm anomalies and weakened offshore winds. The weakened AUSM leads to the same anomalies but with the opposite polarities. Our observational data analysis and numerical experiments reveal that the WP-like anomalies are excited by the propagation of stationary Rossby waves generated by anomalous upper-level divergent wind from NAUS that extends into the Northern Hemisphere subtropical jet. The climatological Hadley circulation is essential in this process. The concomitant anomalous diabatic heating over East Asia and feedback forcing by transient eddies along the Pacific storm track act to further amplify the WP-like response.
\end{abstract}

KEYWORDS: Teleconnections; Monsoons; Climate variability; Interannual variability

\section{Introduction}

Sea surface temperature (SST) variability in the tropics changes convective activity and thereby influences the extratropics by forcing quasi-stationary Rossby waves (Hoskins and Karoly 1981; Hoerling and Kumar 2002). The resultant persistent meanders of the extratropical westerlies sometimes cause extreme climatic conditions that exert significant impacts on our society. El Niño-Southern Oscillation (ENSO) is the most dominant mode of air-sea coupled variability in the tropical Pacific and therefore has been documented extensively. Throughout its life cycle, ENSO induces various teleconnections, influencing global climate (Horel and Wallace 1981; Trenberth et al. 1998; Alexander et al. 2002). Due to its slow evolution compared to the intrinsic time scale of the atmosphere, ENSO provides a basis for seasonal predictability to those regions under its influence, which has motivated many studies on its teleconnections.

Typically, ENSO peaks in boreal winter (Larkin and Harrison 2002) and induces prominent remote impacts. Statistically,

\footnotetext{
๖ Denotes content that is immediately available upon publication as open access.
}

Supplemental information related to this paper is available at the Journals Online website: https://doi.org/10.1175/JCLI-D-210202.s1.

Corresponding author: Shion Sekizawa, shion@atmos.rcast.utokyo.ac.jp wintertime midlatitude East Asia tends to be warmer (colder) than usual during El Niño (La Niña) (e.g., Trenberth et al. 1998). Sakai and Kawamura (2009) revealed that anomalous convective activity over the Maritime Continent and tropical Indian Ocean due to the ENSO-induced anomalous Walker circulation modulates the East Asian winter monsoon through propagations of stationary Rossby waves along the subtropical jet waveguide. Ueda et al. (2015) found a significant tendency for heavy (light) snowfall winters over Japan to be characterized by wave propagation from the Maritime Continent forced by enhanced (suppressed) convective activity. Thus, anomalous convective activity around the Maritime Continent forced by tropical SST variabilities such as ENSO is important for seasonal prediction in wintertime East Asia.

Many studies have investigated the relationship between tropical rainfall and SST (e.g., Trenberth and Shea 2005; Wu and Kirtman 2007; Kumar et al. 2013). For example, Wu and Kirtman (2007) examined local correlations of rainfall with underlying SST and its tendency to identify regimes of air-sea interaction based on the relative importance of SST forcing and atmospheric forcing. They showed that this relative importance has strong seasonality in some regions, including the tropical southeastern Indian Ocean (SEIO). In this region, seasonal-mean rainfall is positively correlated with underlying SST during austral winter and spring as an indication of dominant SST forcing to the atmosphere, primarily associated with the Indian Ocean dipole (IOD; Saji et al. 1999). During austral summer, by contrast, the correlation is weak or even negative, indicating the dominance of atmospheric forcing to the ocean (Hendon et al. 2012). The local negative correlation between precipitation and SST does not necessarily mean there is no 
influence from tropical SST variabilities, because convective activity can be modified by remote SST variability through the anomalous Walker circulation. However, Sekizawa et al. (2018) revealed that the SST-unforced component of rainfall variability is dominant in summertime northern Australia (NAUS) as a manifestation of the internal variability of the Australian summer monsoon (AUSM).

The AUSM is characterized as a period during which the trade easterlies are replaced by the monsoon westerlies, and it typically onsets in late December and retreats in early March (Holland 1986; Hendon and Liebmann 1990a; Drosdowsky 1996; Kajikawa et al. 2010; Evans et al. 2014). The monsoon westerlies bring abundant moisture from the climatologically warm SEIO to NAUS, sustaining pronounced convective activity and associated rainfall. We note that the monsoon season is different from the rainfall season, which onsets earlier in spring when the land surface becomes wet enough to stimulate the plant growth (Lo et al. 2007). The relationship between the interannual AUSM variability and ENSO has been extensively documented. The AUSM tends to onset earlier during La Niña than during El Niño, while there is almost no significant dependence of the retreat date on the ENSO phases (Holland 1986; Drosdowsky 1996; Kajikawa et al. 2010; Evans et al. 2014). This indicates a seasonal weakening of ENSO impacts on the AUSM from austral spring to summer. Indeed, NAUS rainfall anomalies are more strongly correlated with ENSO in austral spring than in summer (Drosdowsky and Williams 1991; Risbey et al. 2009), even though ENSO peaks in summer. Hendon et al. (2012) found that predictability for seasonalmean NAUS rainfall becomes lower in austral summer than in spring. They attributed this predictability decrease to the reversal of the climatological-mean surface winds over the SEIO from easterly to westerly. Under the monsoonal westerlies in summer, anomalous westerlies over the SEIO forced by enhanced convection in NAUS intensify surface wind speed and thus act to lower SST. In this manner, the atmospheric forcing on the ocean dominates, and therefore SST may no longer support persistent anomalous convection in NAUS. We note, however, that despite no support from local or remote SST anomalies, the summertime NAUS rainfall still exhibits strong interannual variability, being energized through wind-evaporation feedback over the SEIO (Sekizawa et al. 2018).

Anomalous convective activity forced by tropical SST anomalies often induces teleconnection that raises the potential predictability for seasonal prediction in the extratropics. By contrast, convection variability that is not constrained by tropical SST anomalies may limit the seasonal predictability and is thus worthy of investigation from the perspective not only of scientific interest but also of operational seasonal prediction. Sekizawa et al. (2018) pointed out that anomalous convective activity associated with the internal AUSM variability can excite remote influence on the extratropics in a similar manner to that associated with ENSO. However, the mechanisms for the teleconnection from the AUSM variability remain to be clarified, which is the aim of the present study.

This paper is structured as follows. In section 2, we describe datasets and numerical models used in this study. Section 3 examines fundamental properties of the interannual AUSM (a) Precip. correl. with the AUSM index based on 9 stations $(\bullet)$

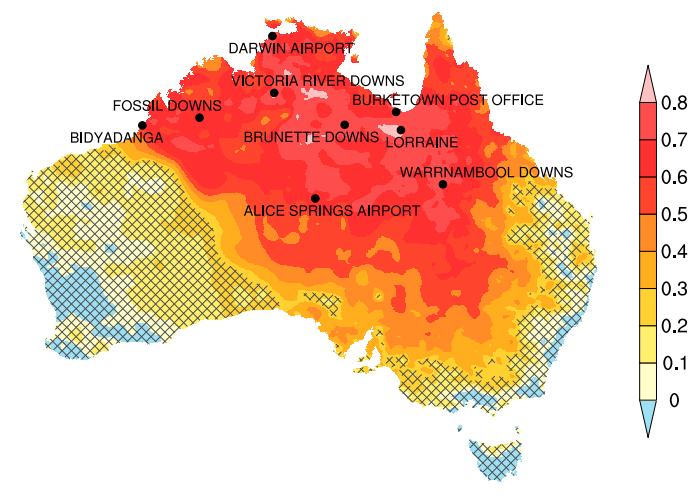

(b) AUSM index ( $)$ \& Niño3.4 SST (-)

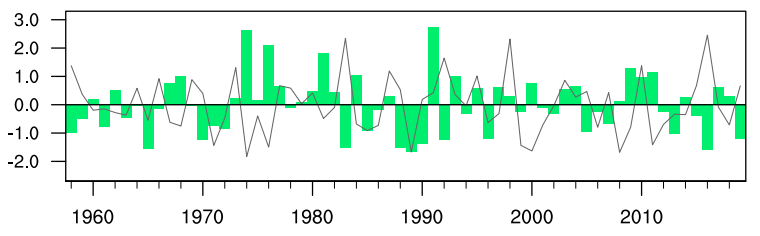

FIG. 1. (a) The nine stations used for defining our rainfall-based AUSM index (dots) and the correlation coefficient between JFmean rainfall based on AWAP (1958-2016) and the AUSM index (shading). Areas with significance that does not exceed the $95 \%$ confidence level are hatched. (b) Standardized time series of the JF-mean AUSM index (green bars) and Niño-3.4 SST (gray line).

variability. Section 4 assesses the remote influence on the northern extratropics, especially East Asia and the western North Pacific, followed by an investigation of the mechanisms in section 5 . We provide a summary and concluding remarks in section 6 .

\section{Data and methods}

\section{a. Observational data and analyses}

We use rain gauge data for 1958-2019 obtained from the Australian Bureau of Meteorology. Since we are interested in interannual variability of the AUSM in its peak season, January-February (JF)-mean rainfall observed at the nine stations shown in Fig. 1a is averaged for each year to define an AUSM index. Shading in Fig. 1a illustrates the distribution of the correlation coefficient between the AUSM index and local JF-mean rainfall based on the Australian Water Availability Project (AWAP) dataset with $0.05^{\circ} \times 0.05^{\circ}$ resolution (Jones et al. 2009). Significant positive correlations over +0.6 cover the entire NAUS and extend to its south in the middle of the continent, while rainfall in Western Australia and along the Pacific coast is almost uncorrelated with the AUSM index.

We use many other meteorological variables from the Japanese 55-year Reanalysis (JRA-55) of the global atmosphere produced by the Japan Meteorological Agency (Kobayashi et al. 2015), which has $1.25^{\circ} \times 1.25^{\circ}$ horizontal resolution and 37 isobaric levels available from 1958. JRA-55 provides three-dimensional diabatic heating fields separately as large-scale condensation, convective 
condensation, radiative heating, and vertical diffusion. We sum them up to use it as forcing of the linear baroclinic model (LBM) described later. We also use data from Hadley Centre Sea Ice and SST (HadISST) with resolution of $1^{\circ} \times 1^{\circ}$ (Rayner et al. 2003).

To evaluate remote impacts of the AUSM variability on East Asia in more detail, we use two datasets from Asian Precipitation-Highly Resolved Observational Data Integration Toward Evaluation of Water Resources (APHRODITE), based primarily on instrumental measurements obtained from a rain gauge-observation network: the Monsoon Asia precipitation dataset, version 1101, with its extension 1101_EX (Yatagai et al. 2012) available from 1958 through 2015, and the dailymean temperature dataset, version 1808 (Yasutomi et al. 2011) available from 1961 through 2015. These APHRODITE datasets cover the domain $15^{\circ} \mathrm{S}-55^{\circ} \mathrm{N}, 60^{\circ}-150^{\circ} \mathrm{E}$ with resolution of $0.25^{\circ} \times 0.25^{\circ}$. We also examine subarctic sea ice and snow depth anomalies associated with the AUSM variability. Monthly sea ice concentrations are taken from the National Oceanic and Atmospheric Administration (NOAA) Optimum Interpolation (OI) SST data, version 2 (Reynolds et al. 2002) with resolution of $1^{\circ} \times 1^{\circ}$ available from 1982 . For snow depth, we use monthly snow water equivalent data from the European Space Agency (ESA) GlobSnow, version 3 (Takala et al. 2011), which covers the Northern Hemisphere with $25-\mathrm{km}$ resolution, based on station-based measurements and satellite observations available from 1982 to 2018. We use this dataset after interpolation onto a $0.5^{\circ} \times 0.5^{\circ}$ latitude-longitude grid system.

In the following, the analysis period varies depending on dataset used, and thus we specify it in a figure caption or the text wherever necessary. Statistical significance of linear correlation and regression is assessed through the two-tailed $t$ test with degrees of freedom based on the number of sample years. A linear trend has been locally removed from any variable fields beforehand. The regressed anomalies are scaled to a unit standard deviation of the corresponding regressor, including the AUSM index.

\section{b. Atmospheric general circulation model}

To ensure the robustness of the AUSM teleconnection, we conducted a numerical simulation with the Geophysical Fluid Dynamics Laboratory (GFDL) Atmospheric Model version 2.1 (Anderson et al. 2005). The model has horizontal resolution of $\sim 220 \mathrm{~km}$ and consists of 24 vertical levels. We use the $200-\mathrm{yr}$ output of a simulation in which a climatological seasonal cycle of SST is repeated without any interannual variability. The SST climatology has been derived for the 1982-98 period from the NOAA OISST (Reynolds et al. 2007). Atmospheric interannual variability in this simulation is thus unforced by SST anomalies. Sekizawa et al. (2018) have confirmed that the simulation exhibits the distinct maximum of JF-mean convection variability around NAUS, representing the predominance of internal AUSM variability.

\section{c. Linear baroclinic model}

To examine causality and mechanisms of the teleconnection associated with the AUSM variability, we conducted numerical experiments with a linear baroclinic model (LBM) developed by
Watanabe and Kimoto (2000). This primitive equation model is linearized about a prescribed three-dimensional basic state and simulates the dry dynamical response to imposed diabatic heating or vorticity forcing. The model has horizontal and vertical resolutions of T42 and 20 levels in $\sigma$ coordinates, respectively, with biharmonic diffusion of $e$-folding time of $1 \mathrm{~h}$ for the largest wavenumber and vertical diffusion of $e$-folding time of 1000 days. We also apply linear damping with $e$-folding time of 0.5 days in $\sigma \geq 0.945$ and $\sigma \leq 0.025,5$ days at $\sigma=0.900,15$ days at $\sigma=0.830$, and 30 days in $0.035 \leq \sigma \leq 0.745$. The amplitude of the response is somewhat sensitive to these parameters, but the response pattern is not. Here, we regard the average of the response from the 31 st to 45 th days of the integration as the steady response.

\section{Interannual variability of the AUSM}

The JF-mean AUSM index (green bars in Fig. 1b) and Niño$3.4 \mathrm{SST}\left(5^{\circ} \mathrm{S}-5^{\circ} \mathrm{N}, 170^{\circ}-120^{\circ} \mathrm{W}\right.$; gray line in Fig. $\left.1 \mathrm{~b}\right)$ are correlated at -0.26 , which is marginally significant at the $95 \%$ confidence level. This significant but weak correlation suggests that ENSO is not the major driver of the seasonalmean AUSM activity. Indeed, Sekizawa et al. (2018) found virtually zero correlation between their AUSM index and Niño-3.4 SST for the period of 1979-2015 when the ENSO-AUSM relationship was even weaker (Fig. S1 in the online supplemental material). Such multidecadal modulations of the ENSO-AUSM relationship has been pointed out in relation to the interdecadal Pacific oscillation (Cai et al. 2010; Zhu 2018). Thus, we consider that the interannual AUSM variability may be largely unforced by ENSO, although tropical SST variability can still exert some influence.

Figures $2 \mathrm{a}$ and $2 \mathrm{~b}$ represent JF and preceding SeptemberOctober (SO) mean anomalies, respectively, of SST and land surface air temperature (SAT) at the 2-m level both regressed onto the AUSM index. Reflecting the weak negative correlation of the AUSM index with the Niño-3.4 SST, significant signals of La Niña and the Indian Ocean basinwide cooling are observed, but their amplitude is relatively weak. Although it is rather weak, a cool SST anomaly forms around NAUS only in $\mathrm{JF}$, under the enhanced evaporation and weaker insolation due to the stronger AUSM (Sekizawa et al. 2018). SAT also decreases locally over NAUS associated with the stronger AUSM. These cold anomalies collocated with enhanced convection indicate the dominance of atmospheric forcing to the surface, consistent with Hendon et al. (2012) and Sekizawa et al. (2018). Repeating this analysis after removing local SST and SAT anomalies regressed onto JF-mean Niño-3.4 SST yields similar anomaly patterns in the SEIO-Australian sector, highlighting the local response of SST and land SAT (Fig. S2a). There is virtually no SST signal around NAUS prior to the anomalous AUSM activity (Fig. 2b; see also Fig. S2b). In particular, there is no signal of the IOD, which develops usually in austral winter through spring and exerts a significant impact on Australian rainfall (e.g., Cai et al. 2011; Risbey et al. 2009). These results confirm that a major portion of the AUSM variability is unforced by tropical SST variability. 
(a) SST \& SAT anom.in JF

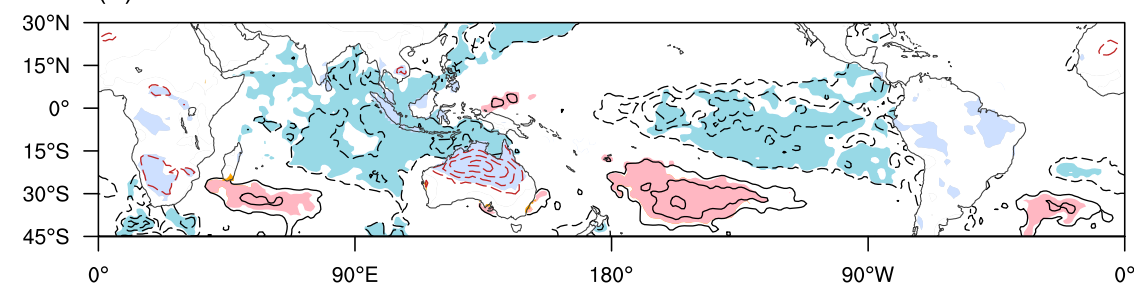

(b) SST \& SAT anom. in preceding SO

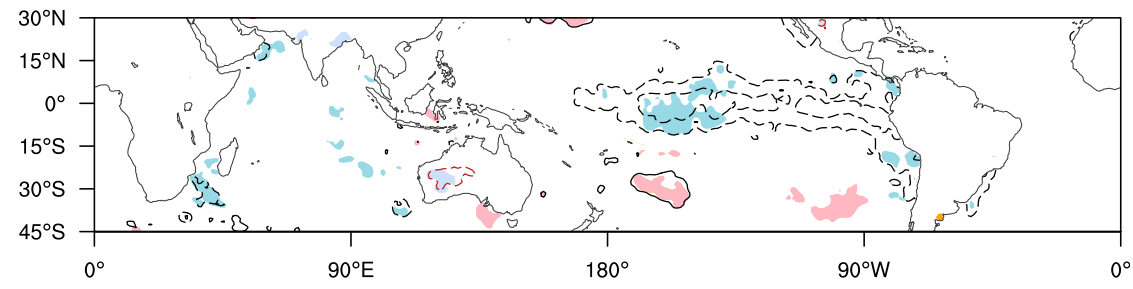

(c) Precipitation \& 10m wind anom. in JF

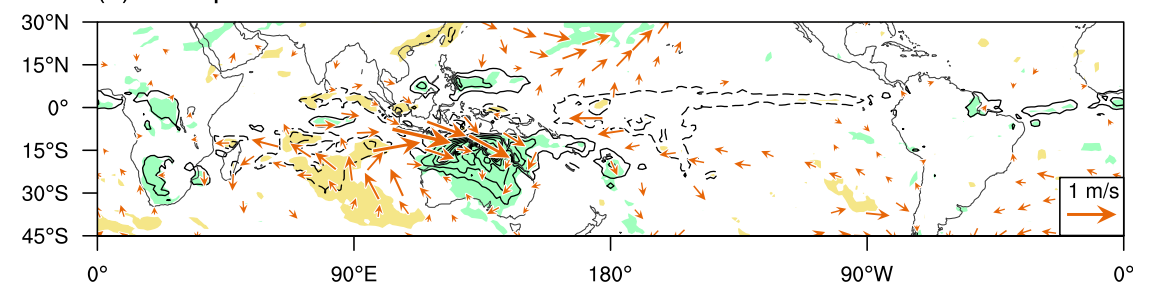

FIG. 2. (a) JF-mean and (b) preceding SO-mean SST and land SAT anomalies and (c) JF-mean precipitation (contours) and 10-m wind (vectors) anomalies regressed onto the AUSM index, based on HadISST and JRA-55 (1958-2019). Contour intervals for SST, SAT, and precipitation are $0.1^{\circ} \mathrm{C}, 0.3^{\circ} \mathrm{C}$, and $0.3 \mathrm{~mm} \mathrm{day}^{-1}$, respectively. Solid and dashed contours indicate positive and negative anomalies, respectively, with zero contours omitted. Color shading represents the corresponding confidence level of $95 \%$. In (c), vectors are plotted only where either the zonal or meridional component is statistically significant at the $95 \%$ confidence level, with the scaling given at the lower-right corner.

JF-mean anomalies in precipitation and 10-m wind regressed onto the AUSM index feature local intensification of the AUSM system (Fig. 2c; see also Fig. S2c). The positive precipitation anomaly is confined to NAUS, as also shown in Fig. 1a. In contrast, convective activity is suppressed over the subtropical southern Indian Ocean coincidentally with the anomalous equatorward winds. The anomalous cyclonic circulation forms as a Rossby-wave response to the enhanced AUSM (Matsuno 1966; Gill 1980), corresponding to an intensification of the climatological-mean monsoonal circulation. This anomalous cyclonic circulation accompanies the intensification of lowlevel westerly winds over the tropical SEIO and the Arafura Sea. These features of rainfall and low-level wind anomalies are again very similar to those shown in Hendon et al. (2012) and Sekizawa et al. (2018). Sekizawa et al. (2018) argued that this internal variability is locally sustained through windevaporation feedback within the AUSM system, but not directly correlated with the Madden-Julian oscillation despite the dominance of intraseasonal variability in summertime rainfall over NAUS (Hendon and Liebmann 1990b; Wheeler et al. 2009). Another positive precipitation anomaly is observed around the Philippines in association with the strong AUSM in Fig. 2c, but it disappears when the ENSO-related anomalies are removed (Fig. S2c).

\section{Remote influence of the AUSM variability}

\section{a. Atmospheric teleconnection}

In this section, we demonstrate that the interannual variability of AUSM not only affects local weather conditions over Australia but also exerts remote climatic impacts on East Asia and the western North Pacific. Figure 3a shows JF-mean anomalies of $850-\mathrm{hPa}$ streamfunction and winds regressed onto the AUSM index. As manifested also in the surface wind anomalies (Fig. 2c), a significant cyclonic anomaly develops over Australia as a Rossby wave response (Matsuno 1966; Gill 1980) to the enhanced AUSM activity. In addition, there is a distinct meridional dipole of streamfunction anomalies over the extratropical western North Pacific. The dipole consists of anomalous cyclonic and anticyclonic lobes east of Japan and in the vicinity of Kamchatka, respectively, resembling the positive western Pacific (WP) pattern (Wallace and Gutzler 1981). 


\section{JF-mean anomalies (AUSM)}

(a) $850 \mathrm{hPa}$ streamfunction \& wind anom.

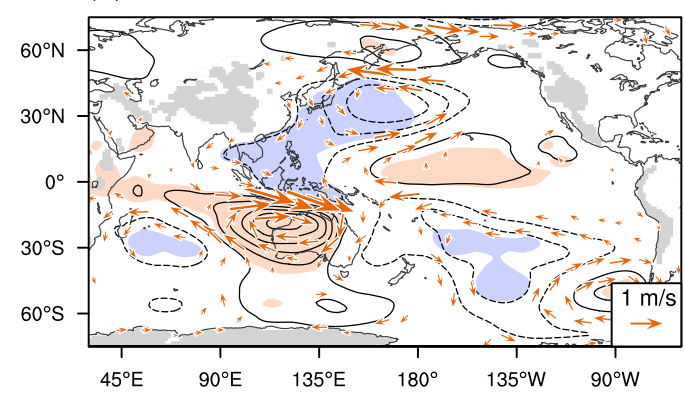

(c) SLP anom.

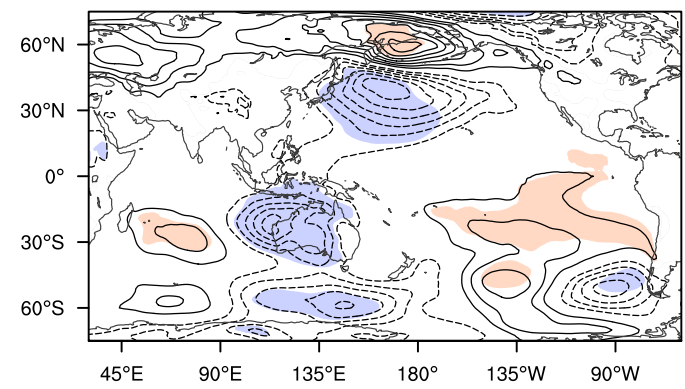

(b) $300 \mathrm{hPa}$ streamfunction anom. \& WAF

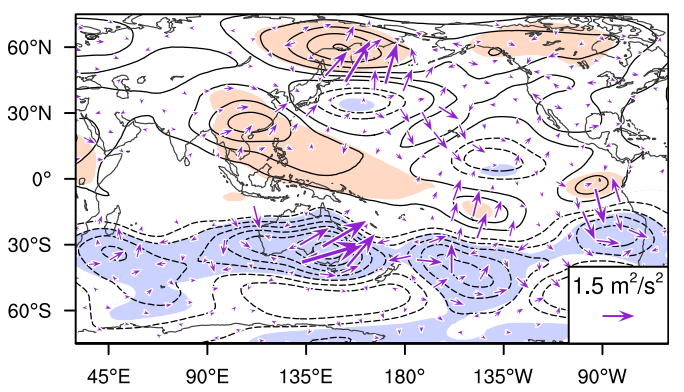

(d) $850 \mathrm{hPa}$ temperature anom.

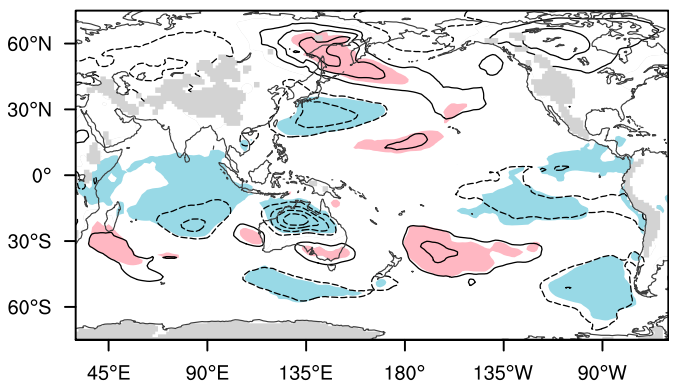

FIG. 3. JF-mean anomalies of (a) 850-hPa streamfunction, (b) 300-hPa streamfunction, (c) SLP, and (d) 850-hPa temperature regressed onto the AUSM index (contours) based on JRA-55 (1958-2019), with contour intervals of (a) $3 \times 10^{5} \mathrm{~m}^{2} \mathrm{~s}^{-1}$, (b) $5 \times 10^{5} \mathrm{~m}^{2} \mathrm{~s}^{-1}$, (c) $0.2 \mathrm{hPa}$, and (d) $0.2^{\circ} \mathrm{C}$. Solid and dashed contours indicate positive and negative anomalies, respectively, with zero contours omitted. Color shading represents the corresponding confidence level of $95 \%$. Vectors in (a) and (b) indicate 850 -hPa wind anomalies and 300-hPa Rossby wave activity flux [Eq. (1)], respectively, whose scaling is given at the lower-right corner of each panel. In (a), vectors are plotted only where either the zonal or meridional component is statistically significant at the $95 \%$ confidence level.

The WP pattern modulates the East Asian winter monsoon (Takaya and Nakamura 2013; Tanaka et al. 2016). Indeed, the cyclonic anomaly is associated with anomalous northwesterlies in East Asia (Fig. 3a).

The corresponding 300-hPa streamfunction anomalies are illustrated in Fig. $3 b$ together with the associated wave-activity flux $\mathbf{W}$, formulated for stationary Rossby waves by Takaya and Nakamura (2001) as

$$
\mathbf{W}=\frac{\cos \varphi}{2|\overline{\mathbf{u}}|}\left[\begin{array}{c}
\frac{\bar{u}}{a^{2} \cos ^{2} \varphi}\left(\psi_{\lambda}^{\prime 2}-\psi^{\prime} \psi_{\lambda \lambda}^{\prime}\right)+\frac{\bar{v}}{a^{2} \cos \varphi}\left(\psi_{\lambda}^{\prime} \psi_{\varphi}^{\prime}-\psi^{\prime} \psi_{\lambda \varphi}^{\prime}\right) \\
\frac{\bar{u}}{a^{2} \cos \varphi}\left(\psi_{\lambda}^{\prime} \psi_{\varphi}^{\prime}-\psi^{\prime} \psi_{\lambda \varphi}^{\prime}\right)+\frac{\bar{v}}{a^{2}}\left(\psi_{\varphi}^{\prime 2}-\psi^{\prime} \psi_{\varphi \varphi}^{\prime}\right)
\end{array}\right],
$$

where $a$ denotes the radius of Earth, $\overline{\mathbf{u}}$ the climatological JFmean flow with its zonal component $\bar{u}$ and meridional component $\bar{v}$, and $\psi^{\prime}$ the streamfunction anomaly; the subscripts refer to the partial derivative with respect to longitude $\lambda$ and latitude $\varphi$. In the upper troposphere (Fig. 3b), a distinct anticyclonic anomaly covers the Australian continent, indicating a baroclinic structure of the local response to the enhanced convection. In the Northern Hemisphere, a wavelike pattern is prominent from the north of the Maritime Continent to the subarctic Far East, which is likely a poleward stationary Rossby wave train as suggested by the northeastward waveactivity flux. This wave train is similar to the wavelike patterns identified with wintertime climate variability in Japan by Sakai and Kawamura (2009) and Ueda et al. (2015).

The zonal sea level pressure (SLP) gradient between the Siberian high and Aleutian low controls the East Asian winter monsoon intensity (Hanawa et al. 1988). A negative SLP anomaly in the southwestern portion of the Aleutian low associated with the strong AUSM (Fig. 3c) intensifies the zonal SLP gradient and thus the East Asian winter monsoon (Fig. 3a), bringing a significant cold anomaly to Japan and its east (Fig. 3d). A warm anomaly observed around the Sea of Okhotsk is due to the anomalous easterlies that induce anomalous warm advection from the climatologically warmer North Pacific toward colder Siberia (Figs. 3a,d). As found by Tanaka et al. (2016), these warm and cold advection anomalies act to reinforce the dipolar thermal anomalies, as a key maintenance mechanism of the WP pattern. This baroclinic energy gain and additional feedback forcing from the anomalous storm track activity (shown later) are consistent with the diverging northeastward wave-activity flux associated with the WP-like response (Fig. 3b).

Figure 4 compares JF-mean anomalies in 500-hPa geopotential height associated with the AUSM variability and 
(a) 500hPa height anom. (AUSM)

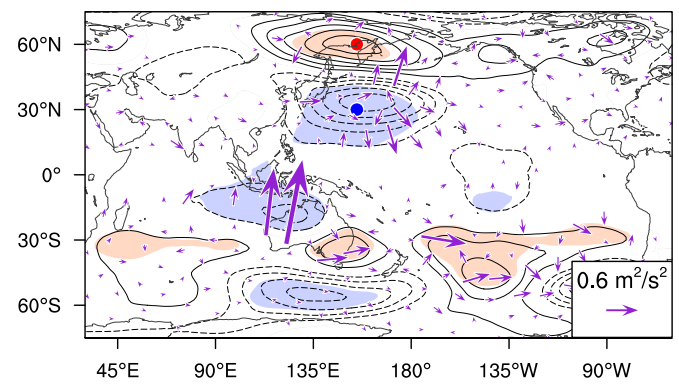

(c) $500 \mathrm{hPa}$ height anom. (ENSO)

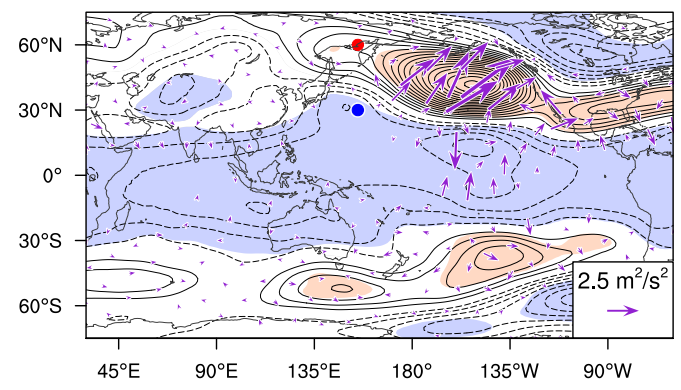

(b) Variance fraction (AUSM)

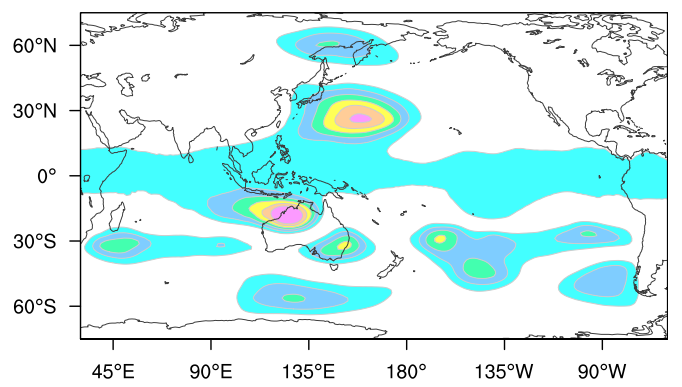

(d) Variance fraction (ENSO)

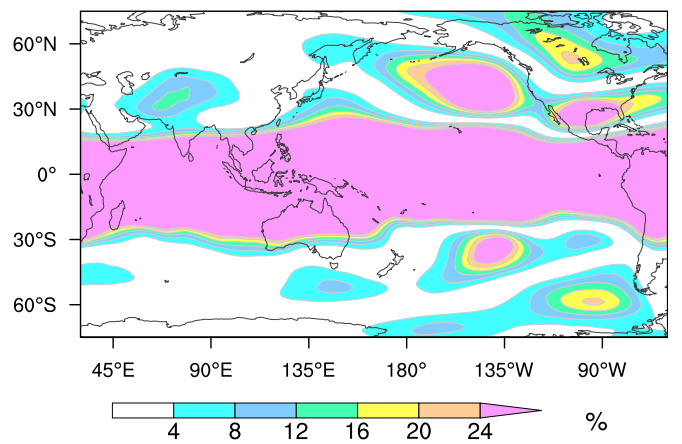

FIG. 4. (left) JF-mean 500-hPa geopotential height anomalies regressed onto JF-mean (a) AUSM index and (c) (sign-reversed) Niño-3.4 SST and associated Rossby wave-activity flux based on JRA-55 (1958-2019). Solid and dashed contours with intervals of $3 \mathrm{~m}$ indicate positive and negative anomalies, respectively, with zero contours omitted. Color shading represents the corresponding confidence level of $95 \%$. Red and blue dots denote the centers of action of the WP pattern, for which normalized anomalies are used for defining the WP index. The vector scaling is given at the lower-right corner of each panel. (right) Associated local variance fraction due to the regressed anomalies onto (b) the AUSM index and (d) Niño-3.4 SST.

ENSO (500-hPa height is often used for evaluating potential predictability; e.g., Zwiers 1996; Zheng et al. 2000). The regressed height anomalies onto the AUSM index again show a clear dipole pattern over the western North Pacific (Fig. 4a) as a characteristic of the WP pattern. In fact, the correlation coefficient reaches +0.43 between the AUSM index and WP index (defined as the difference of standardized 500-hPa height anomalies between the two centers of action at $60^{\circ} \mathrm{N}, 155^{\circ} \mathrm{E}$ and $30^{\circ} \mathrm{N}, 155^{\circ} \mathrm{E}$; Wallace and Gutzler 1981). Furthermore, nearly $25 \%$ of the interannual variance of JF-mean $500-\mathrm{hPa}$ height east of Japan (around the southern center of action of the WP-like response) is related to the AUSM variability (Fig. 4b), which is larger than its ENSO counterpart (Fig. 4d). Since the remote influence of ENSO strongly projects onto the Pacific-North American (PNA) pattern (Horel and Wallace 1981; Wallace and Gutzler 1981) as shown in Fig. 4c, the associated variance fraction is particularly high over the eastern North Pacific (Fig. 4d). Unlike suggested by Horel and Wallace (1981), the projection of the JF-mean ENSO anomalies onto the WP pattern is moderate although statistically significant. In fact, the correlation between the JF-mean WP index and Niño-3.4 SST is -0.32 , which is weaker than the WP-AUSM correlation. In the same figure as Fig. 4 but based on DecemberFebruary mean anomalies (Fig. S3), the relationship between
ENSO and WP becomes somewhat stronger, suggesting a subseasonal weakening of ENSO's remote influence from early to late winter. Sakai and Kawamura (2009) attributed this modulation to the subseasonal evolution of the ENSO-forced tropical convection anomaly pattern from early winter to midwinter.

Our AGCM experiment confirms that the AUSM variability and associated circulation anomalies in the Northern Hemisphere as observed in Figs. 2 and 3, respectively, can emerge as purely atmospheric internal variability. Consistent with its observational counterpart (Fig. 2c), the interannual variability of NAUS precipitation accompanies modulations in the AUSM intensity and associated monsoonal circulation (Fig. 5a), although the model overestimates a precipitation anomaly with the opposite sign over the tropical Indian Ocean. The cyclonic anomaly east of Japan is also reproduced (Fig. 5b), with its center of action displaced eastward to the central North Pacific. Nevertheless, significant cold and dry anomalies are evident in East Asia and their spatial distributions are similar to their observed counterpart (Figs. 5a,c). The subpolar anticyclonic anomaly and associated warm anomaly are also reproduced (Figs. 5b,c), again with northeastward displacement into the vicinity of the Chukchi Sea around $70^{\circ} \mathrm{N}, 180^{\circ}$. These results indicate robustness of the 


\section{JF-mean anomalies (AUSM in AGCM experiment)}

(a) Precipitation \& 10m wind anom.

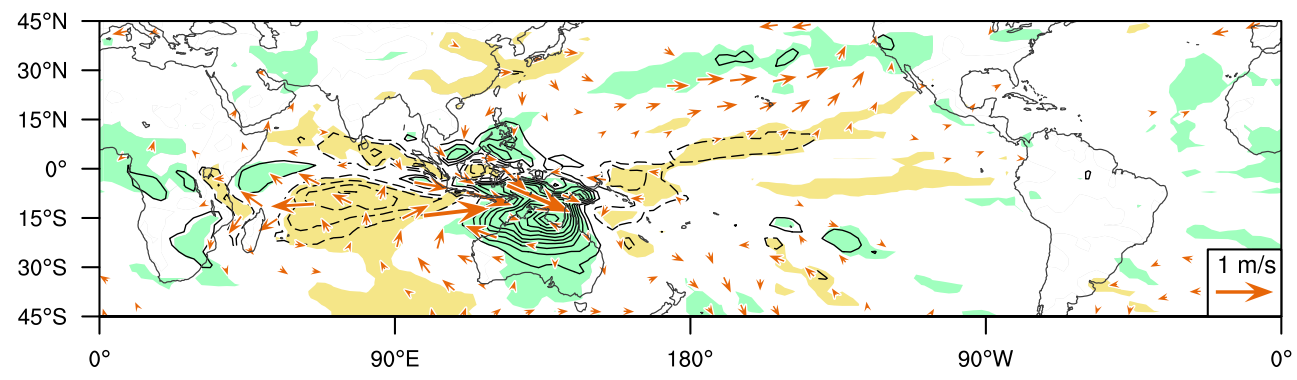

(b) $500 \mathrm{hPa}$ height anom.

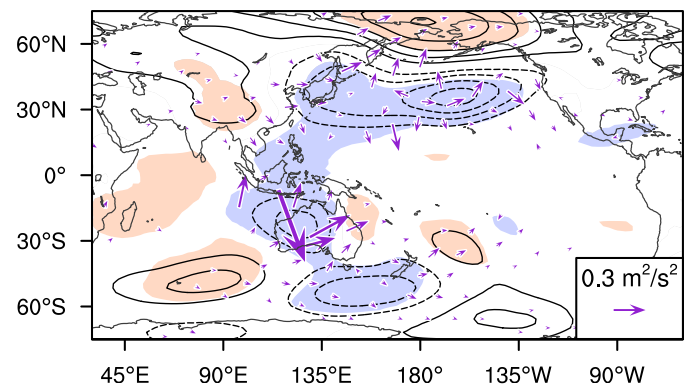

(c) $850 \mathrm{hPa}$ temperature anom.

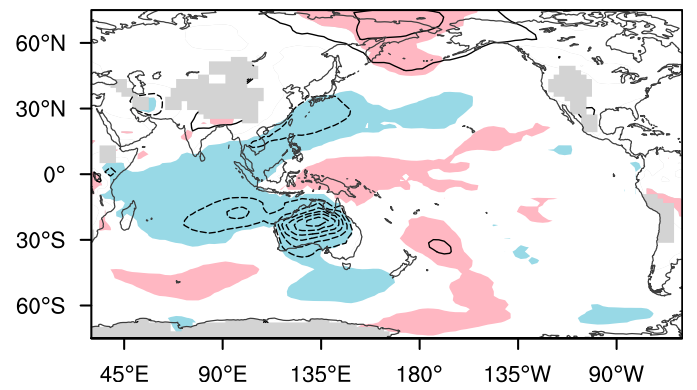

FIG. 5. JF-mean anomalies of (a) 10-m wind (vectors) and precipitation, (b) 500-hPa geopotential height, and (c) 850-hPa temperature (contours) regressed onto the JF-mean precipitation averaged over the Australian continent north of $20^{\circ} \mathrm{S}$, based on the AGCM experiment with fixed climatological SST. Contour intervals are (a) $0.3 \mathrm{~mm} \mathrm{day}^{-1}$, (b) $3 \mathrm{~m}$, and (c) $0.2^{\circ} \mathrm{C}$. Solid and dashed contours indicate positive and negative anomalies, respectively, with zero contours omitted. Color shading represents the corresponding confidence level of $95 \%$. Vectors for the 500-hPa Rossby wave activity flux are superimposed on (b). In (a), vectors are plotted only where either the zonal or meridional component is statistically significant at the $95 \%$ confidence level. The vector scaling is given at the lower-right corner of each panel.

interhemispheric linkage between the AUSM variability and the WP pattern.

\section{b. Impacts on regional climate}

To examine the impact of AUSM variability on the wintertime East Asian climate in more detail, the high-resolution land SAT and precipitation anomalies are regressed onto the AUSM index together with the JRA-55 data over the ocean (Figs. 6a,c). For comparison, the corresponding anomalies regressed onto the Niño-3.4 index, whose sign has been flipped to feature a La Niña condition, are also shown (Figs. 6b,d). Consistent with the low-level temperature anomalies shown in Fig. 3d, the enhanced AUSM yields significant surface cold anomalies over the East China Sea, the Korean Peninsula, western Japan, and the subtropical Pacific south and southeast of Japan (Fig. 6a). These cold anomalies are accompanied by anomalous surface northwesterlies, indicating the intensification of the East Asian winter monsoon. Warm anomalies are observed over the Sea of Okhotsk associated with anomalous surface easterlies. The temperature anomalies due to ENSO are similar in structure with a slightly larger magnitude (Fig. 6b). The cold anomalies associated with ENSO are accompanied by anomalous northerlies or northeasterlies (Fig. 6b), which may be a part of the anomalous Philippine Sea cyclone identified by Wang et al. (2000).

In strong AUSM years, precipitation decreases in southern China, the East China Sea, and the subtropical Pacific to the south of Japan (Fig. 6c), which corresponds to the anomalous descending motion (shown in the next section). Rainfall (or snowfall) significantly increases along the northwestern coast of Japan under the enhanced monsoonal northwesterlies, whereas the opposite is the case in association with ENSO (Fig. 6d). Elsewhere, the ENSO-associated precipitation anomalies are distributed similarly, despite being somewhat stronger.

Figure 6e denotes JF-mean anomalies of sea ice concentration and snow water equivalent regressed onto the AUSM index. Consistent with the warm and onshore wind anomalies over the Sea of Okhotsk (around $45^{\circ}-60^{\circ} \mathrm{N}, 140^{\circ}-150^{\circ} \mathrm{E}$; Figs. 3a,d and 6a), the sea ice extent shrinks locally in association with the stronger AUSM. Okhotsk sea ice is reduced also under the warm anomalies in La Niña winters (Figs. 6b,f). As a remote influence of the enhanced AUSM, sea ice extent tends to expand over the Bering Sea (Fig. 6e), which may be induced by the anomalous northerlies associated with the anticyclonic response (Fig. 3a). With ENSO influence, by contrast, 
(a) Temperature anom. (AUSM)

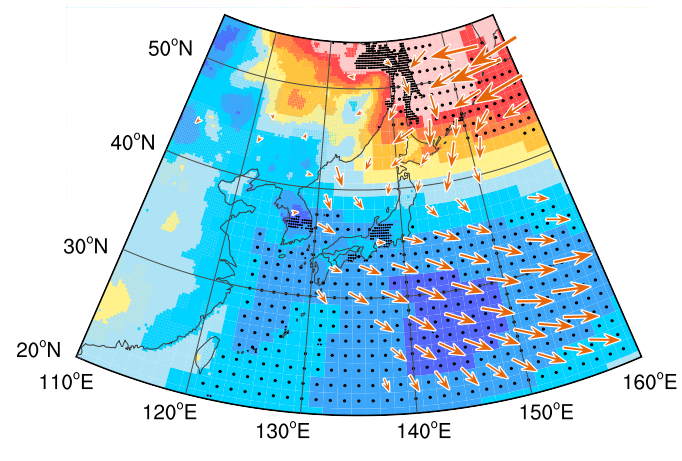

(b) Temperature anom. (ENSO)

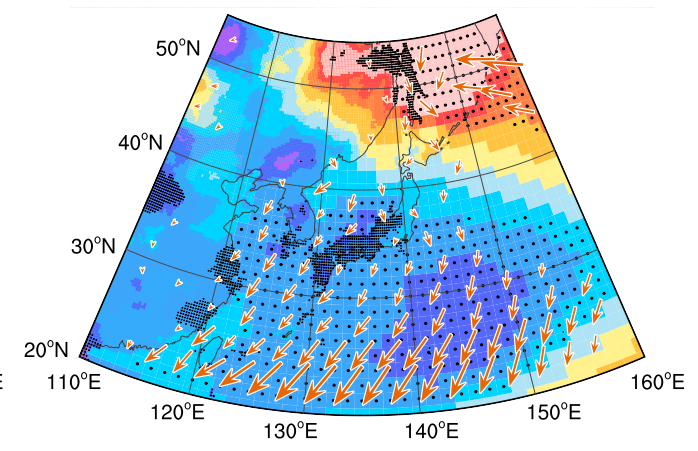

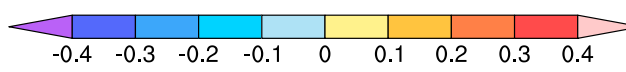

${ }^{\circ} \mathrm{C}$

$0.5 \mathrm{~m} / \mathrm{s}$

(c) Precipitation anom. (AUSM)

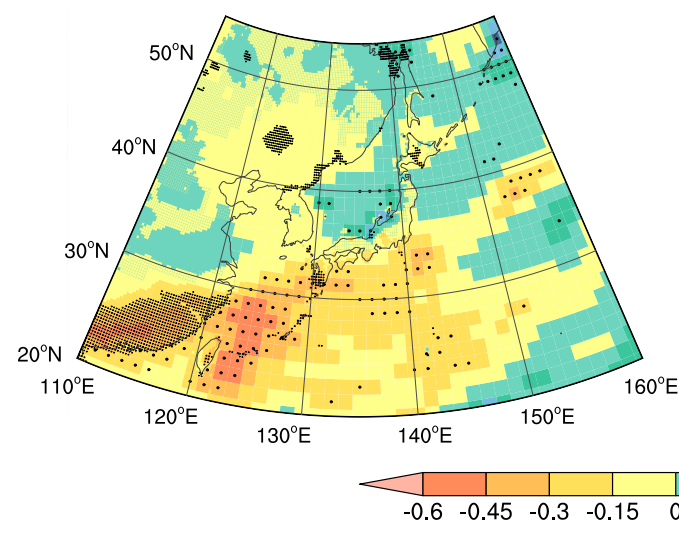

(d) Precipitation anom. (ENSO)

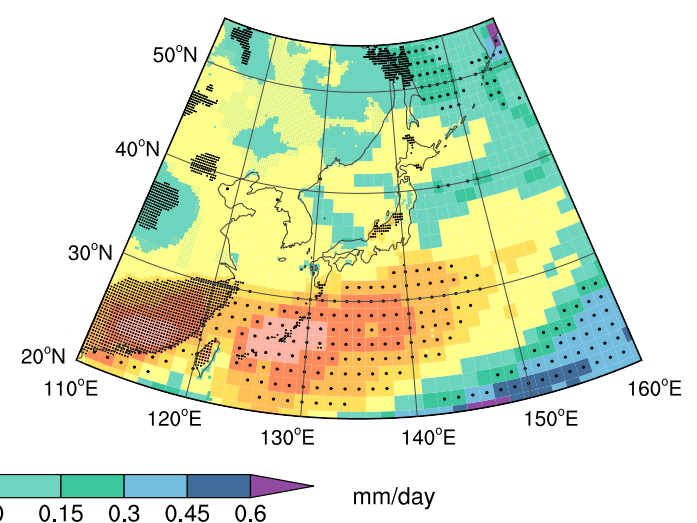

(e) Sea ice \& Snow anom. (AUSM)

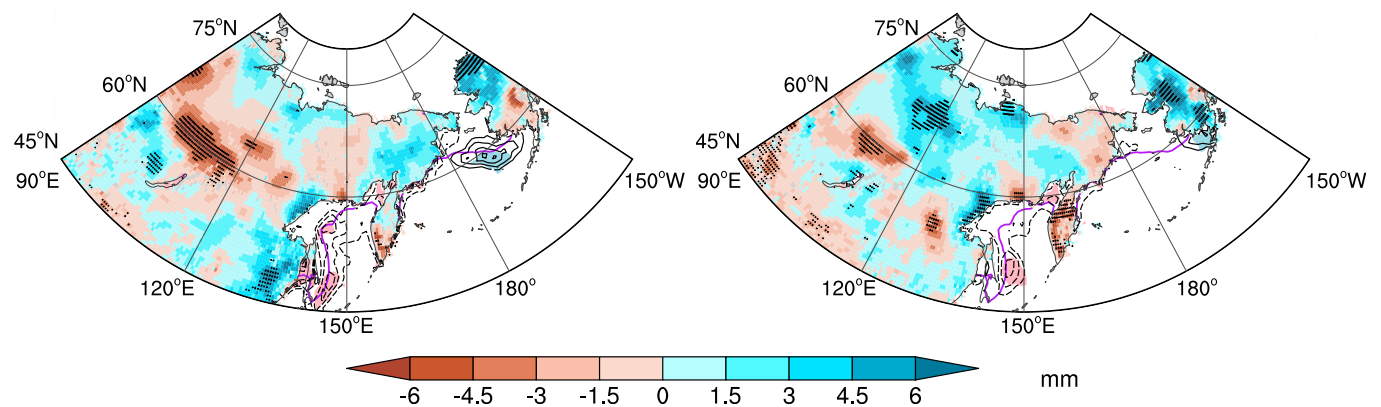

FIG. 6. JF-mean anomalies of (a),(b) SAT, (c),(d) precipitation, and (e),(f) sea ice concentration (contours) and snow water equivalent (shading), regressed onto (a),(c),(e) the AUSM index and (b),(d),(f) Niño-3.4 SST. Stippling denotes the anomalies significant at the $90 \%$ confidence level. (a),(b) SAT anomalies over land and the ocean are based on APHRODITE (1961-2015) and JRA-55 (1958-2019), respectively. Vectors indicate 10-m wind anomalies based on JRA-55 (1958-2019), whose scaling is given at the bottom of (b), and plotted only where either the zonal or meridional component is statistically significant at the $90 \%$ confidence level. In (c) and (d), precipitation anomalies over land and the ocean are based on APHRODITE (1958-2015) and JRA-55 (1958-2019), respectively. In (e) and (f), sea ice concentration and snow water equivalent anomalies are based on OISST (1982-2019) and GlobSnow (1979-2018), respectively. For sea ice, solid and dashed contours with intervals of $2 \%$ indicate positive and negative anomalies, respectively, and zero contours omitted. Shading over the ocean denote the sea ice concentration anomalies significant at the $90 \%$ confidence level. Thick purple contours indicate climatological sea ice concentration of $50 \%$. 
(a) $S^{\prime} \& \zeta^{\prime}$

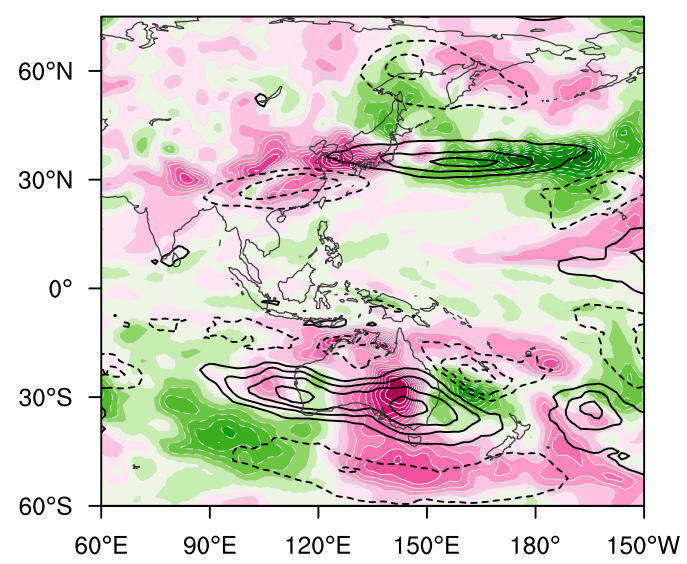

(c) $S_{2}, \quad v_{x}^{\prime} \& \bar{\zeta}$

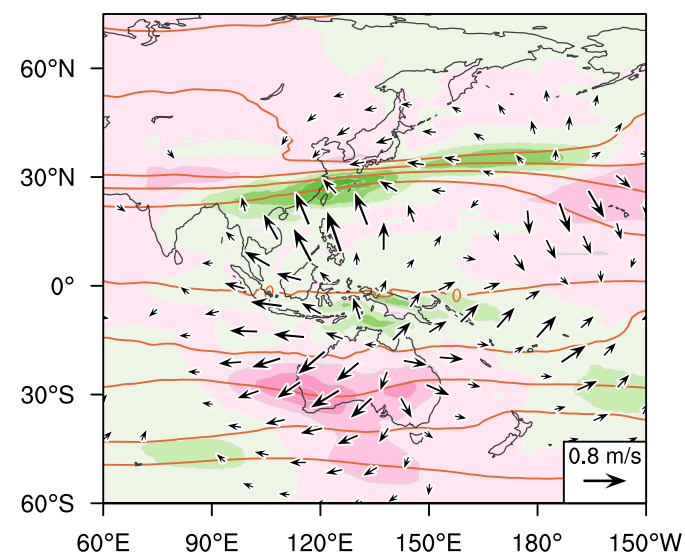

(b) $S_{1} \& \nabla \cdot v_{x}^{\prime}$

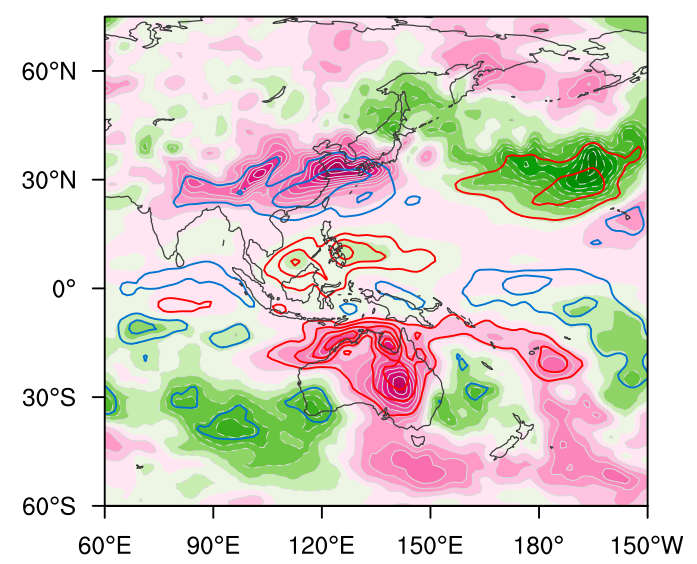

(d) $S_{3}+S_{4} \& \bar{v}_{x}$

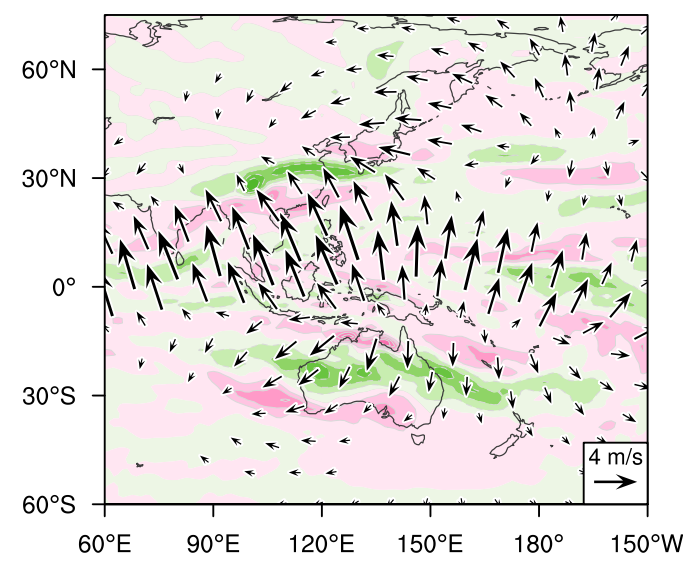

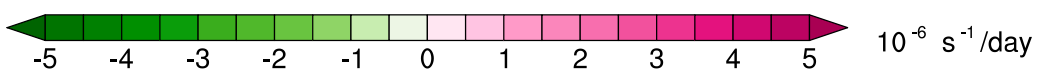

FIG. 7. (a) RWS (shading) vertically averaged between the 250- and 150-hPa levels based on JF-mean anomalies regressed onto the AUSM index. Associated positive and negative vorticity anomalies are superimposed with solid and dashed black contours, respectively, with intervals of $1.5 \times 10^{-6} \mathrm{~s}^{-1}$. (b)-(d) Decomposition of the RWS into the contributions from (b) $S_{1}$, (c) $S_{2}$, and (d) $S_{3}+S_{4}$ in Eq. (3). Red and blue contours in (b) indicate anomalous divergence and convergence, respectively, with intervals of $3 \times 10^{-7} \mathrm{~s}^{-1}$. Brown contours in (c) indicate climatological absolute vorticity, with contour intervals of $3 \times 10^{-5} \mathrm{~s}^{-1}$. Vectors in (c) and (d) indicate anomalies and climatology, respectively, of divergent winds with scaling given at the lower-right corner of each panel.

no significant sea ice anomalies are observed in the Bering Sea (Fig. 6f), where the anomalous westerlies dominant (not shown). Interestingly, both AUSM variability and ENSO tend to be concomitant with significant snow depth anomalies to the north of Lake Baikal, but their linkage to atmospheric anomalies is unclear.

\section{Teleconnection mechanisms}

\section{a. Rossby wave source analysis}

In section $4 \mathrm{a}$, we found the Rossby wave train propagating northeastward from the north of the Maritime Continent associated with the AUSM variability. To investigate how the anomalous NAUS convection forces the wave train, we analyze Rossby wave source (RWS) $S^{\prime}$ defined as

$$
S^{\prime}=-\nabla \cdot\left(\mathbf{v}_{\chi} \zeta\right)^{\prime}
$$

where $\mathbf{v}_{\chi}$ denotes divergent wind and $\zeta$ the absolute vorticity, and the prime signifies an anomaly (Sardeshmukh and Hoskins 1988). Figure 7a shows a map of RWS vertically averaged between the 250- and 150-hPa levels based on the JF-mean anomalies regressed onto the AUSM index, together with the regressed vorticity anomalies. The vertical averaging is applied because the anomalies are strong along the 
meridionally inclined tropopause, which is higher in the tropics and lowers toward the midlatitudes. The RWS in (2) may be linearized as

$$
\begin{aligned}
S^{\prime} \approx & S_{1}+S_{2}+S_{3}+S_{4}=-\bar{\zeta} \nabla \cdot \mathbf{v}_{\chi}^{\prime}-\mathbf{v}_{\chi}^{\prime} \cdot \nabla \bar{\zeta} \\
& -\zeta^{\prime} \nabla \cdot \overline{\mathbf{v}}_{\chi}-\overline{\mathbf{v}}_{\chi} \cdot \nabla \zeta^{\prime},
\end{aligned}
$$

where the overbar signifies a climatological-mean quantity. In Figs. 7b-d, the RWS shown in Fig. 7a is decomposed into the three contributions in (3): the stretching effect by anomalous divergence acting on the climatological absolute vorticity [the first term on the rhs of (3), $\left.S_{1}\right]$, advection of the climatological absolute vorticity by anomalous divergent wind (second term, $S_{2}$ ), and terms related to vorticity anomalies and the climatological divergent winds (third and fourth terms, $S_{3}+S_{4}$ ).

In Fig. 7a, a cyclonic (positive) RWS extends from China to Japan (magenta shading), which can induce the zonally elongated cyclonic vorticity anomaly (solid black contours) to its downstream along the subtropical jet. This vorticity source arises mostly from the stretching effect due to anomalous convergence (blue contours in Fig. 7b) acting on the climatological absolute vorticity. Shiozaki et al. (2021) showed that a similar but negative RWS over East Asia during El Niño induces an anticyclonic anomaly around Japan. By contrast, the anticyclonic vorticity anomaly over southern China (dashed black contours in Fig. 7a) accompanies no corresponding net negative RWS. Nevertheless, an anticyclonic forcing through $S_{2}$ is collocated with this anticyclonic vorticity anomaly along the subtropical jet (green shading in Fig. 7c), which is due to anomalous poleward divergent winds crossing the climatologically sharp gradient of the absolute vorticity (brown contours) associated with the strong subtropical jet. The $S_{3}$ and $S_{4}$ terms, which are related to the climatological divergent winds and dominated by $S_{4}$, make secondary contributions to the Rossby wave forcing, acting to advect the subtropical anticyclonic vorticity anomalies poleward (Fig. 7d). Section 5 c discusses the potential role of the climatological divergent winds.

Note that the RWS in this analysis, especially $S_{1}$ in the extratropics with strong absolute vorticity, includes vorticity tendencies due to divergence and convergence associated with a Rossby wave train itself. Specifically, anomalous uppertropospheric convergence and midtropospheric subsidence are required just downstream of an anticyclonic anomaly and/or upstream of a cyclonic anomaly in order to retain their barotropic structure if embedded in the vertically sheared westerlies, as in wintertime East Asia. Indeed, Qin and Robinson (1993) referred to $S_{1}$ (and $S_{3}$ ) as the extratropical RWS and $S_{2}$ (and $S_{4}$ ) as the tropical RWS, arguing that the extratropical RWS may be understood by quasigeostrophic dynamics. Besides, the precipitation decreases in East Asia (Fig. 6c), which induce cyclonic $S_{1}$ through anomalous descents (Fig. 7b), can be regarded as remotely induced moist feedback (section 5d). We therefore cannot necessarily separate the cause and effect based on the RWS fields. Considering these issues, we argue that the subtropical anticyclonic anomaly north of the Maritime Continent is likely induced by anomalous poleward divergent winds across the subtropical jet (Fig. 7c), whose contributions are, however, overwhelmed by the vorticity stretching
(Fig. 7b) induced through the quasigeostrophic dynamics and local precipitation decrease (Fig. 6c).

We therefore infer that the cross-equatorial teleconnection can be achieved as follows. Anomalous ascents forced by the enhanced AUSM around $15^{\circ} \mathrm{S}$ induce anomalous divergent winds in the upper troposphere. The anomalous northward divergent winds then converge to generate anomalous descents over East Asia as it reaches the subtropical jet with a steep absolute vorticity gradient. The anticyclonic and cyclonic RWS are induced through $S_{2}$ and $S_{1}$, respectively, over East Asia, which force the midlatitude quasi-stationary Rossby wave. While this wave propagates over the western North Pacific, the WP-like anomaly pattern develops through energy conversion from the background state as shown by Tanaka et al. (2016). They revealed the characteristic of WP pattern as a dynamical mode, which can maintain itself efficiently by converting available potential energy from the baroclinic climatologicalmean flow and therefore can be excited by various kinds of forcing.

\section{b. Steady response to the diabatic heating in NAUS}

To verify this mechanism, we examine the steady response of atmospheric circulation to anomalous diabatic heating with the LBM. We have prescribed the zonally asymmetric JF-mean climatological-mean field as a basic state of the LBM and forced it by the JF-mean anomalies of diabatic heating rate only over NAUS $\left(30^{\circ}-5^{\circ} \mathrm{S}, 105^{\circ}-165^{\circ} \mathrm{E}\right)$ regressed onto the AUSM index (shading in Fig. 8a), both of which had been derived from JRA-55 (1958-2019).

Despite no forcing in the Northern Hemisphere, there are distinct $500-\mathrm{hPa}$ height responses in both the extratropical Northern and Southern Hemispheres (Fig. 8a). The Northern Hemisphere response features a WP-like dipolar pattern as obtained from the observations (Fig. 4a), although the anomalous cyclone slightly displaced northward centered near $40^{\circ} \mathrm{N}$. The corresponding vorticity response and RWS are depicted in Fig. 9. Consistent with the observations (Fig. 7), a cyclonic vorticity response forms east of Japan (black solid contours in Fig. 9a), with a cyclonic vorticity source located upstream due to anomalous convergence extending from northeastern China to northern Japan (magenta shading in Fig. 9b). Unlike in the observations, the anticyclonic vorticity response is not isolated over southern China but extends zonally (dashed black contours). Nevertheless, a weak anticyclonic response maximum forms just east of southern China associated with an anticyclonic vorticity source through $S_{2}$ (green shading in Fig. 9c).

\section{c. Role of the background divergent wind}

The RWS analysis may imply that climatological-mean divergent wind around the Maritime Continent is of secondary importance in the formation of the wave source. If we remove the divergent wind component from the prescribed basic state, however, the remote influence on the Northern Hemisphere almost disappears in the LBM (Fig. 8d). A potential role of the background divergent flow can be inferred from the initial time evolution of the LBM response. Figures 10 and 11 show the time evolution of vorticity tendency in response to NAUS 
(a) AUSM (NAUS)

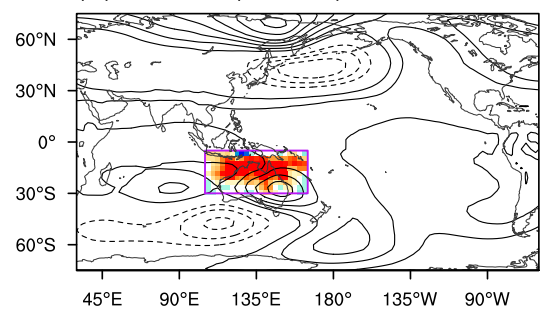

(b) AUSM (East Asia)

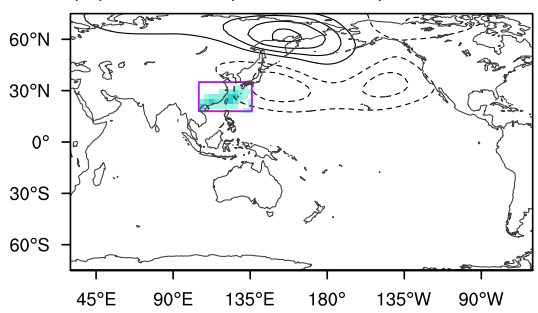

(c) AUSM (Philippines)

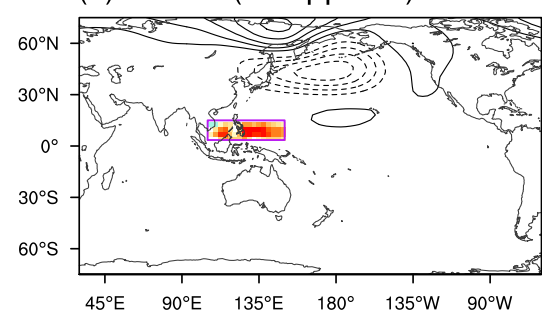

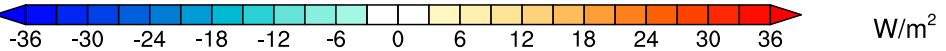

(d) AUSM (NAUS, no div)

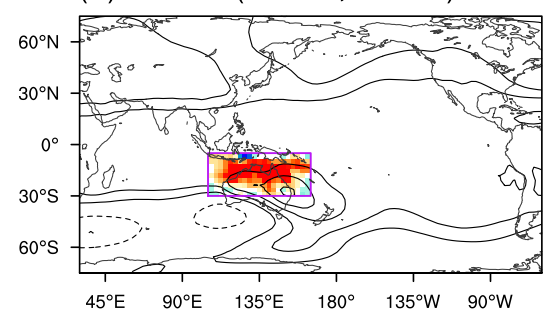

(e) AUSM (submonthly)

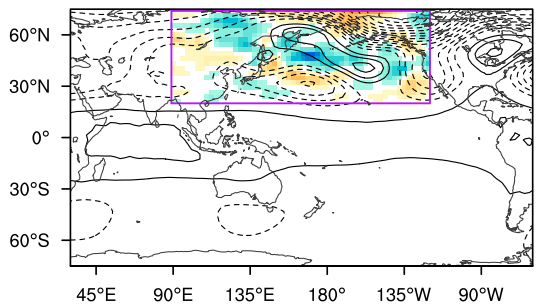

(f) AUSM (transient)

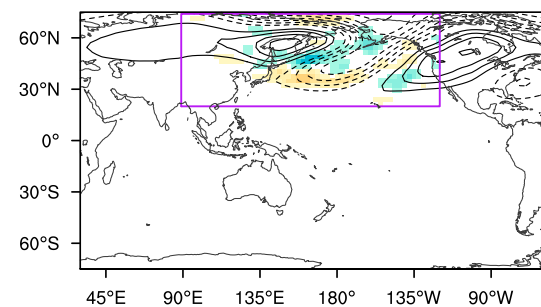

(g) ENSO (MC heating)

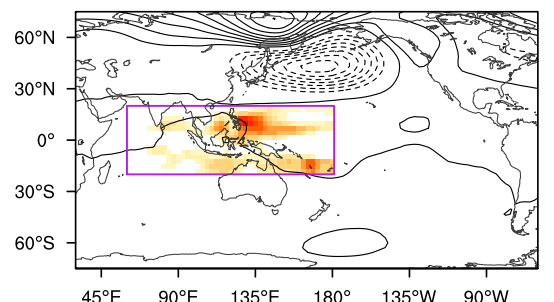

(h) ENSO (Pacific cooling)

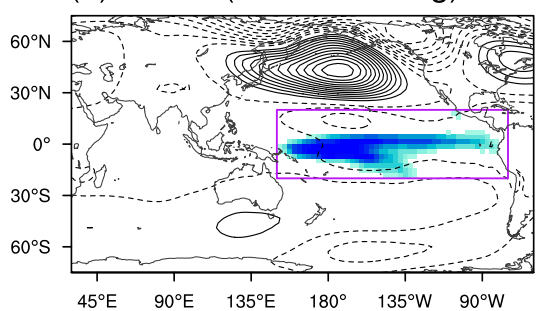

(i) ENSO (MC+Pacific)

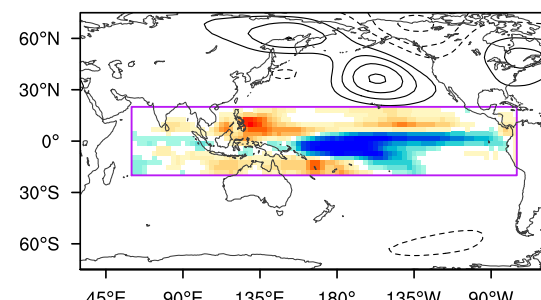

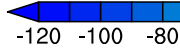

\begin{tabular}{l|l}
\hline & \\
-60 & -40
\end{tabular}

\begin{tabular}{l|l|} 
& 1 \\
\hline & -20
\end{tabular}

20

$\mathrm{W} / \mathrm{m}^{2}$

FIG. 8. Steady responses of 500-hPa geopotential height (contours) in LBM experiments with the JF-mean climatology as the basic state. (a)-(c) Responses to anomalous diabatic heating around (a) NAUS, (b) East Asia, and (c) the Philippines, regressed onto the AUSM index. (d) As in (a), but for the experiment where the divergent wind component is removed from its basic state. (e),(f) Responses to the anomalous heat and vorticity flux forcing due to (e) submonthly and (f) subweekly transient eddies over the North Pacific, regressed onto the AUSM index. (g)-(i) Responses to anomalous diabatic heating over (g) the Maritime Continent (heating only), (h) Pacific (cooling only), and (i) both the Maritime Continent and Pacific (regardless of its sign) regressed onto the -Niño-3.4 SST. Contour intervals are (a)-(f) 1.5 and (g)-(i) $8 \mathrm{~m}$ with solid and dashed contours indicating positive and negative anomalies, respectively, and zero contours omitted. Shading indicates column-integrated (a)-(d),(g)-(i) diabatic heating and (e),(f) eddy heat flux convergence.

heating in the basic state with and without divergent wind components, respectively.

In the full basic state, a negative vorticity response emerges along the equator in about $30 \mathrm{~h}$ after the heating is imposed (Fig. 10a), mainly through negative vorticity advection by both background rotational winds (Fig. 10d) and anomalous divergent winds ( $\mathrm{S}_{2}$; Fig. $10 \mathrm{~g}$; see also Fig. S4d). This negative vorticity tendency gradually spreads northward to reach the vicinity of the subtropical jet for the next $90 \mathrm{~h}$ (Figs. 10b,c). This northward expansion is primarily due to the vorticity advection by the climatological-mean divergent wind $\left(S_{4}\right.$; Fig. 10k; see also Fig. S4k), with an additional contribution from the advection by rotational winds (Fig. 10e). Suppose the response propagates northward over $20^{\circ}$ in latitude within $90 \mathrm{~h}$; the estimated propagation speed is $\sim 7 \mathrm{~m} \mathrm{~s}^{-1}$, which roughly matches the speed of the climatological-mean divergent winds. In this manner, the cross-equatorial background divergent winds advect the initial negative vorticity response northward to the subtropical jet while acting to homogenize the absolute vorticity in the tropics. This process is reminiscent of the axisymmetric model of the Hadley cell by Held and Hou (1980), where upper-tropospheric angular momentum is homogenized within the cell. Hoskins and Yang (2021) have also pointed out that the upper-tropospheric cross-equatorial 
(a) $S^{\prime} \& \zeta^{\prime}$

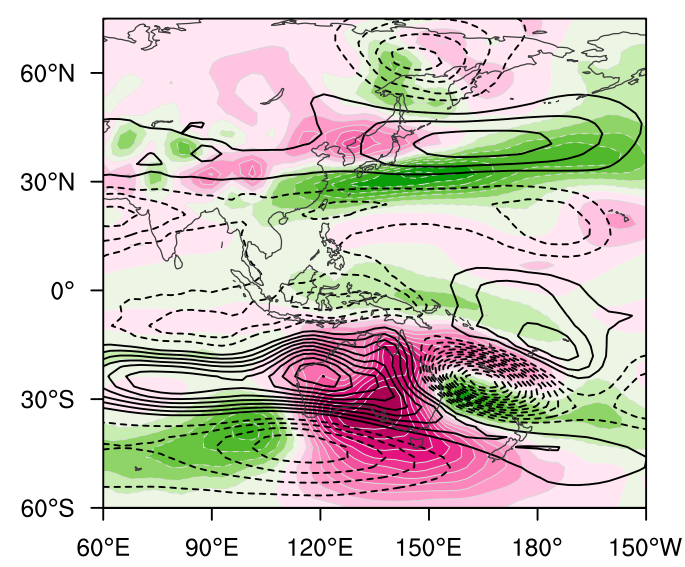

(c) $S_{2}, v_{\chi}^{\prime} \& \bar{\zeta}$

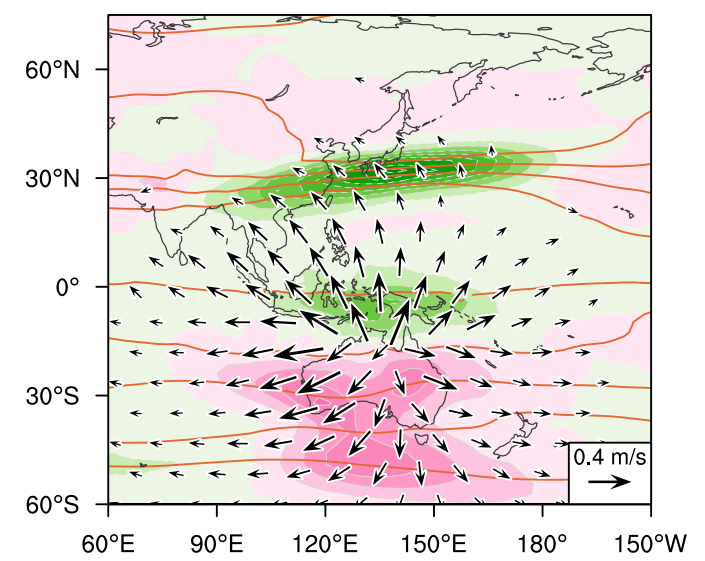

(b) $S_{1} \& \nabla \cdot v_{\chi}^{\prime}$

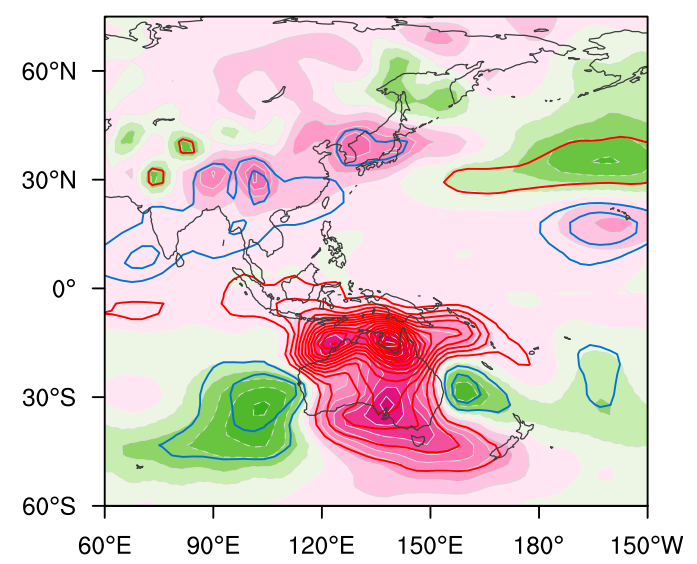

(d) $S_{3}+S_{4} \& \bar{v}_{\chi}$

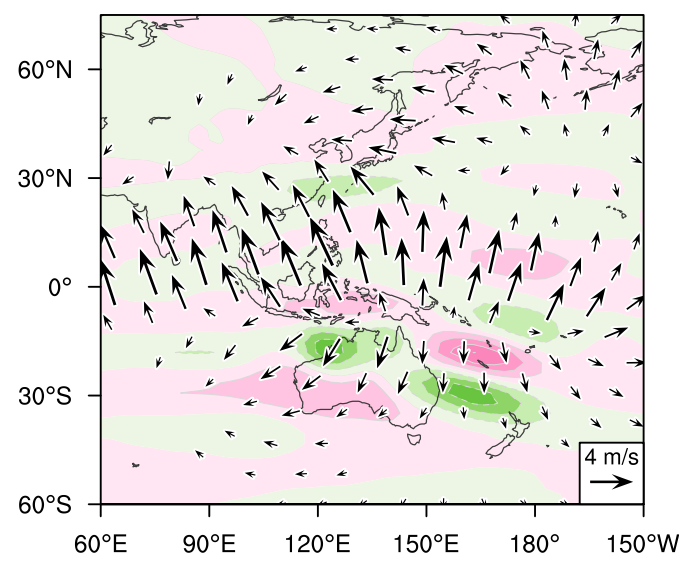

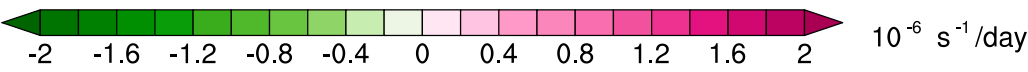

FIG. 9. As in Fig. 7, but for the steady response to the diabatic heating over NAUS in the LBM experiment with the JF-mean climatology as the basic state. Contour intervals are (a) $3 \times 10^{-7}$, (b) $6 \times 10^{-8}$, and (c) $3 \times 10^{-5} \mathrm{~s}^{-1}$.

winds due to active convection over NAUS transport the Southern Hemispheric air with negative absolute vorticity into the Northern Hemisphere.

Note that in the early stage, wave sources $S_{1}+S_{2}$ are generated around the Northern Hemisphere subtropical jet by a weak divergent wind response that acts on the strong absolute vorticity and its meridional gradient (Fig. 10g). These wave sources are then immediately modulated by the secondary circulation associated with the generated Rossby waves and largely offset by the rotational wind advection (Figs. 10e,f,h,i). The pair of weak vorticity anomalies formed earlier in the northern subtropics then amplifies after the arrival of the anomalous negative vorticity originating from the equatorial region (Fig. 10c). Climatological-mean upper-level convergence in the subtropics also acts to amplify the vorticity anomalies ( $S_{3}$; Fig. 101; see also Fig. S4i).

Without background divergent winds, by contrast, the meridional homogenization of vorticity response no longer works.
The equatorial negative vorticity response tends to be advected by the climatological easterlies (Figs. 11a-f) rather than penetrating into the northern subtropics. The anomalous upper-level divergent winds reaching the northern subtropics and associated convergence are somewhat weaker than those in the full basic state case, although $S_{1}+S_{2}$ distribution is similar (Figs. 11i, 10i, and 12). This result suggests that the existence of the climatological Hadley cell ensures the divergent wind anomalies reaching East Asia by amplifying vorticity anomalies along the subtropical jet.

\section{d. Contribution from diabatic heating outside of NAUS and eddy feedback forcing}

Although the LBM qualitatively reproduces the observed teleconnection pattern associated with the AUSM variability, some processes are missing in the above experiment. Here we investigate possible contributions from precipitation anomalies outside of NAUS and feedback forcing from eddies on 


\section{$\mathrm{t}=30 \mathrm{hr}$}
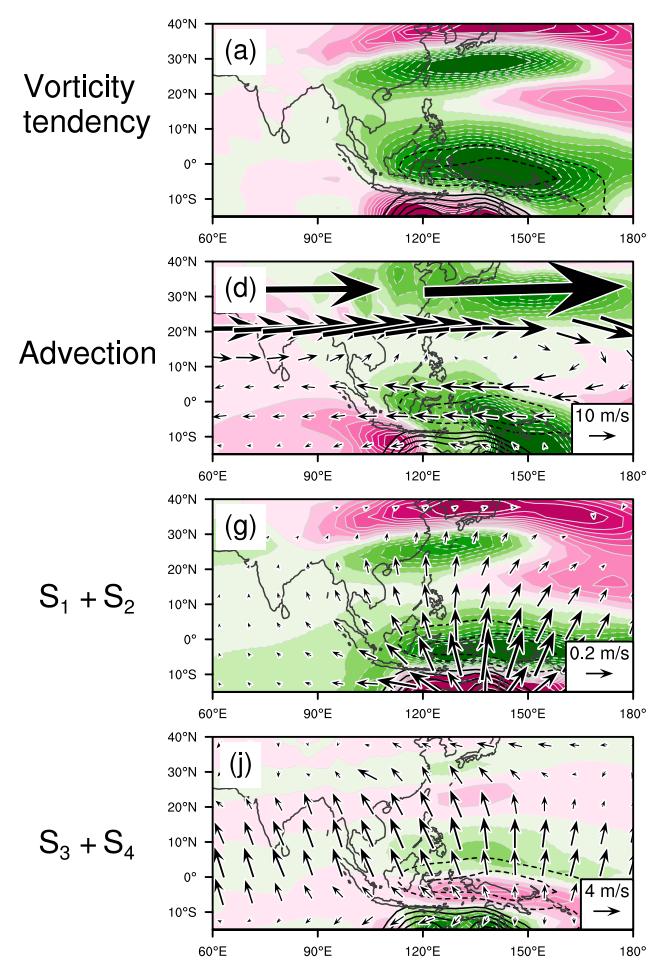
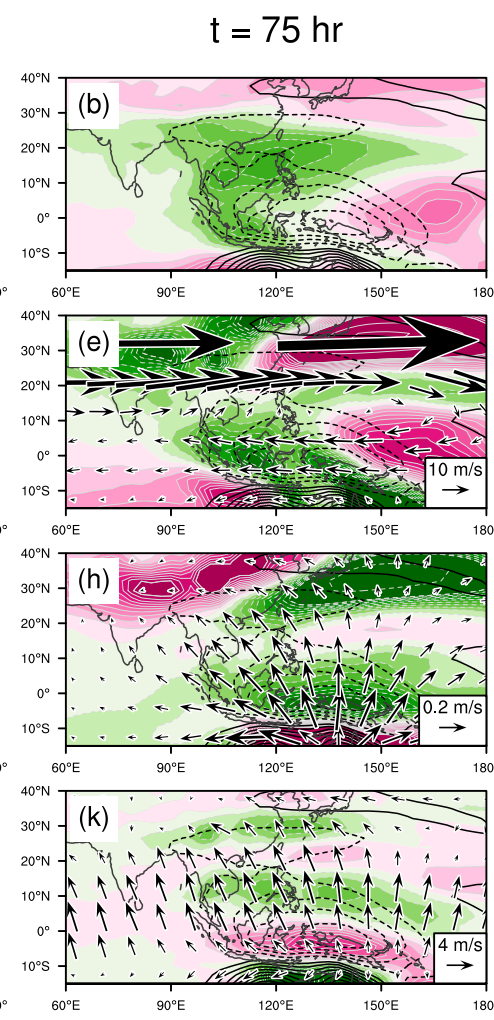

$\mathrm{t}=120 \mathrm{hr}$
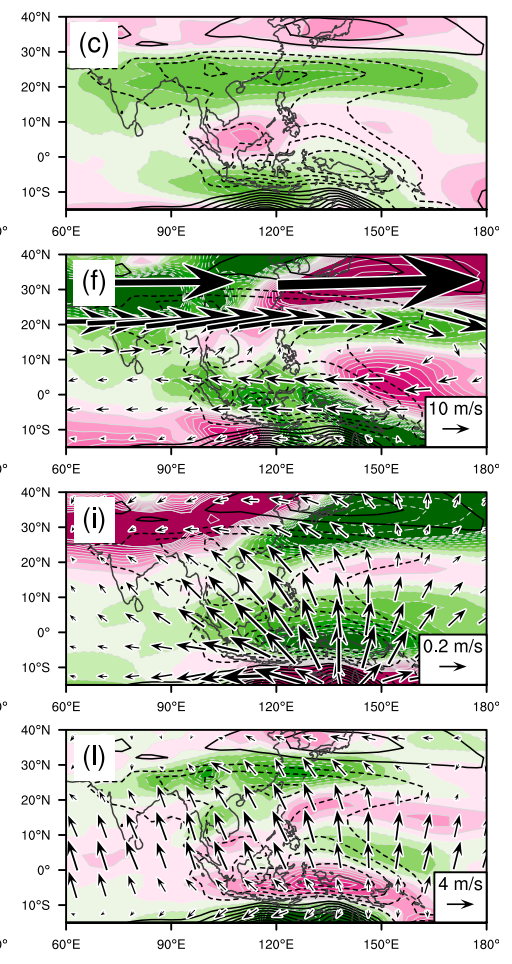

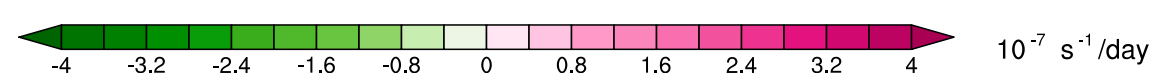

FIG. 10. (a)-(c) Vorticity tendency (shading and white contours) vertically averaged from 250 to $150 \mathrm{hPa}$, and that due to (d)-(f) advection by rotational winds, (g)-(i) $S_{1}+S_{2}$, and (j)-(l) $S_{3}+S_{4}$ in Eq. (3), at (left) $30 \mathrm{~h}$, (center) $75 \mathrm{~h}$, and (right) $120 \mathrm{~h}$ of integration in the LBM experiment with the JF-mean basic state and diabatic heating around NAUS. Contour intervals are $0.4 \times 10^{-7}$ and $4 \times$ $10^{-7} \mathrm{~s}^{-1}$ day $^{-1}$ for the tendency weaker and stronger than $\pm 4 \times 10^{-7} \mathrm{~s}^{-1} \mathrm{day}^{-1}$, respectively. Vectors in (d)-(f), (g)-(i), and (j)-(l) indicate climatological rotational winds, divergent wind response, and climatological divergent winds, respectively, with different scaling as given at the lower-right corner of each panel. Associated positive and negative vorticity responses are superimposed with solid and dashed black contours, respectively, with intervals of $2 \times 10^{-7} \mathrm{~s}^{-1}$.

submonthly time scales. In enhanced AUSM years, convective activity enhances over the South China Sea and east of the Philippines (Fig. 2c), while precipitation decreases in southern China under the anomalous descending motion (Fig. 6c). This precipitation decrease can be induced by the anomalous upperlevel convergence as a response to the diabatic heating anomaly over NAUS (Fig. 9b). As shown in Fig. 8b, the anomalous diabatic cooling located around East Asia $\left(18^{\circ}-35^{\circ} \mathrm{N}, 105^{\circ}-135^{\circ} \mathrm{E}\right)$ also forces a positive WP-like pattern, with a magnitude comparable to the NAUS heating experiment (Fig. 8a). The meridional position is almost identical to the observed WP pattern (Fig. 4a). In addition, the anomalous diabatic heating around the Philippines $\left(4^{\circ}-15^{\circ} \mathrm{N}, 105^{\circ}-135^{\circ} \mathrm{E}\right)$ can also force a dipolar height anomaly pattern that is again similar to the WP pattern (Fig. 8c). The resemblance of the LBM response to diabatic heating/cooling placed at the three different regions is consistent with the dynamical mode nature of the WP pattern (Tanaka et al. 2016).

Modulations of the midlatitude storm-track activity can also contribute to the formation of seasonal atmospheric circulation anomalies (Lau 1988; Lau and Nath 1991). Figure 13 shows the JF-mean anomalies of 850-hPa poleward eddy heat flux and
$300-\mathrm{hPa}$ eddy meridional wind variance regressed onto the AUSM index. Here, eddies are defined as deviations from the JF mean (hereinafter referred to as submonthly eddies; Figs. 13a,b) and high-pass filtered fields (hereinafter referred to as transient eddies; Figs. 13c,d), based on 6-hourly JRA-55 data. We have applied the Lanczos high-pass filter with the cutoff period of 8 days using 121 weights to extract subweekly fluctuations. The $850-\mathrm{hPa}$ poleward eddy heat flux due to submonthly eddies is climatologically large over the Bering Sea and along $40^{\circ} \mathrm{N}$, primarily due to low-frequency and subweekly transient eddies, respectively (blue contours in Figs. 13a,c). In association with the stronger AUSM, the former eddy heat flux significantly enhances, while the latter somewhat weakens (black contours in Fig. 13a). In fact, the weakening of the midlatitude storm track activity is more evident in the transient eddy heat flux (Fig. 13c). The corresponding modulations of submonthly eddy activity are also manifested in upper-level meridional wind variance as the intensification of low-frequency eddy activity over the Sea of Okhotsk and the Bering Sea and the weakening of the midlatitude storm-track activity (Figs. 13b,d). The reduction of 
$\mathrm{t}=30 \mathrm{hr}$
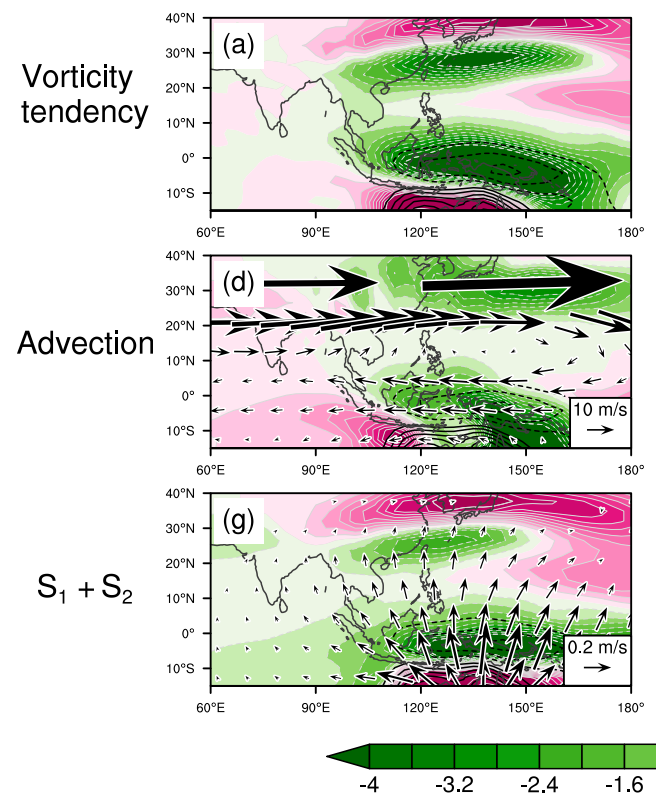

$\mathrm{t}=75 \mathrm{hr}$
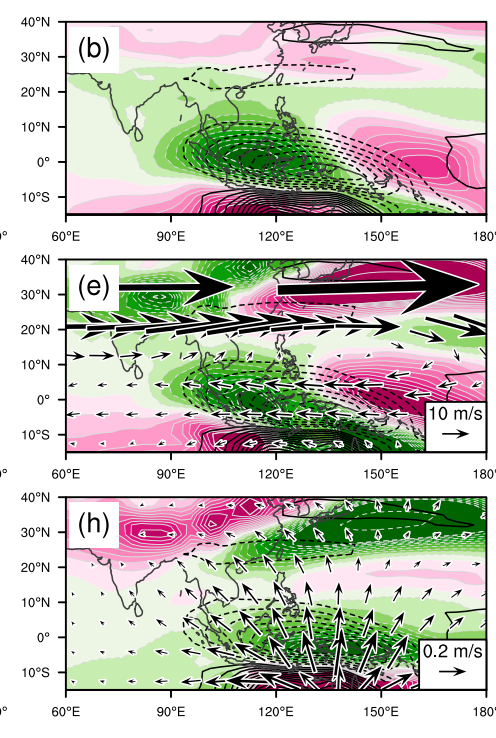

$t=120 \mathrm{hr}$
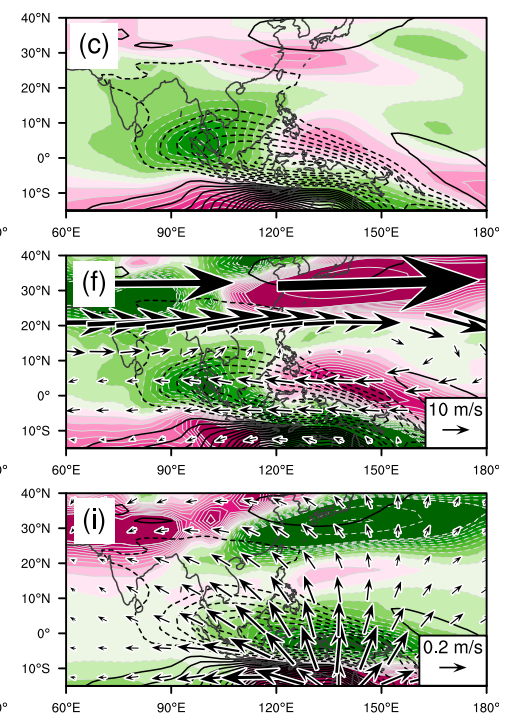

FIG. 11. As in Figs. 10a-i, but for the experiment where the divergent wind component is removed from its basic state. Note that vorticity tendency due to $S_{3}+S_{4}$ in Eq. (3) is constantly zero in this experiment.

poleward heat transport due to the suppressed storm track activity acts to damp the meridional dipole of low-level temperature anomalies associated with the positive WP-like pattern (Fig. 3d). The concurrent anomalous eddy momentum transport, however, may act to maintain the WP-like anomalies. Indeed, Tanaka et al. (2016) showed that positive barotropic feedback forcing by subweekly transient eddies contributes to sustaining the WP pattern, overwhelming the counteracting negative baroclinic eddy feedback forcing.

The role of the anomalous eddy heat and momentum fluxes in the formation of JF-mean anomaly fields is verified through additional LBM experiments with the eddy flux convergence anomalies as forcing. The eddy fluxes have been estimated as horizontal fluxes of temperature and vorticity according to the quasigeostrophic framework based on the 6-hourly eddy fields from JRA-55. The steady LBM response to the anomalous submonthly eddy heat and vorticity forcing over the North Pacific $\left(20^{\circ}-75^{\circ} \mathrm{N}, 90^{\circ} \mathrm{E}-120^{\circ} \mathrm{W}\right)$ features a WP-like meridional dipole with an anticyclonic response over Kamchatka and a cyclonic response southeast of Japan (Fig. 8e). The response to the transient eddy feedback forcing is wavy but projects positively onto the observed WP-like anomalies (Fig. 8f), indicating that the modulated storm track activity acts to amplify the WP-like response to the anomalous AUSM.

\section{e. Regionality in remote induction efficiency}

As shown in Figs. $8 \mathrm{a}-\mathrm{c}$, anomalous diabatic heating or cooling in and around the Maritime Continent tends to yield a steady response similar to the WP pattern. One may wonder whether diabatic forcing placed at any location in the tropics can force a similar response. In other words, we examine how preferable the AUSM variability is to excite the WP-like circulation anomalies. To see this, we have conducted another set of LBM experiments, each forced by localized diabatic heating placed at a grid point $\left(\sim 2.8^{\circ}\right.$ resolution $)$ in the tropics spanning $30^{\circ} \mathrm{S}-30^{\circ} \mathrm{N}$. The basic state is again the zonally asymmetric JF-mean climatology. The vertical heating profile in the $\sigma$ coordinate is adopted from the diabatic heating anomaly in NAUS regressed onto the AUSM index, representing a deep structure with a peak near $\sigma=0.45$ (Fig. 14a). Regardless of whether such deep anomalous convection is possible in reality, we have imposed this vertical profile in all of these hypothetical experiments.

Figure $14 \mathrm{~b}$ summarizes the sign and magnitude of the WPlike meridional dipole responses in $500-\mathrm{hPa}$ height as a function of the heating location in the LBM simulations. Shown at each grid point is the difference of $500-\mathrm{hPa}$ height response between $70^{\circ} \mathrm{N}, 155^{\circ} \mathrm{E}$ and $40^{\circ} \mathrm{N}, 155^{\circ} \mathrm{E}$ normalized by the column-integrated heating rate. We choose these two locations that are $10^{\circ}$ north of those used for defining the WP index in section $4 \mathrm{a}$, recognizing the northward displacement of the LBM response compared to the observed WP pattern (Figs. 4a and 8a). A heating placed in the vicinity of the subtropical jet over Asia tends to show particularly high efficiency in yielding a WPlike response. A positive WP-like response emerges against a heating around the South China Sea and the Red Sea, while a negative response develops with a heating around East Asia and India. In other words, suppressed precipitation in the latter regions can force a positive WP-like response. Besides, a positive WP-like response can be excited with moderate efficiency by a heating placed around the Maritime Continent and the tropical South Pacific. Since NAUS is located immediately south of the Maritime Continent, the AUSM variability can exert the remote influence on the western North Pacific, although with a modest 


\section{Meridional div. wind \& vorticity responses}

(a) With clim. divergent winds

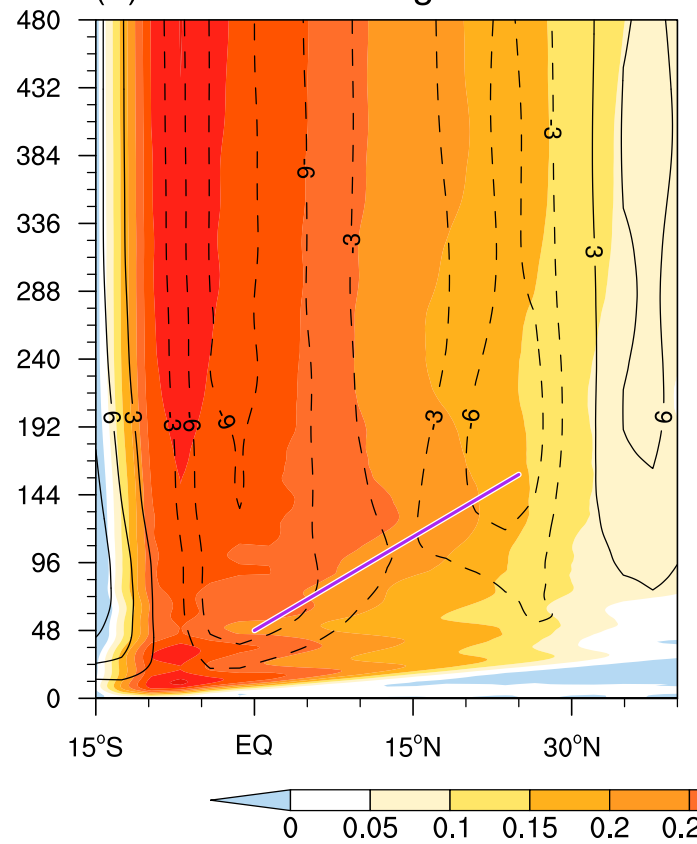

(b) Without clim. divergent winds

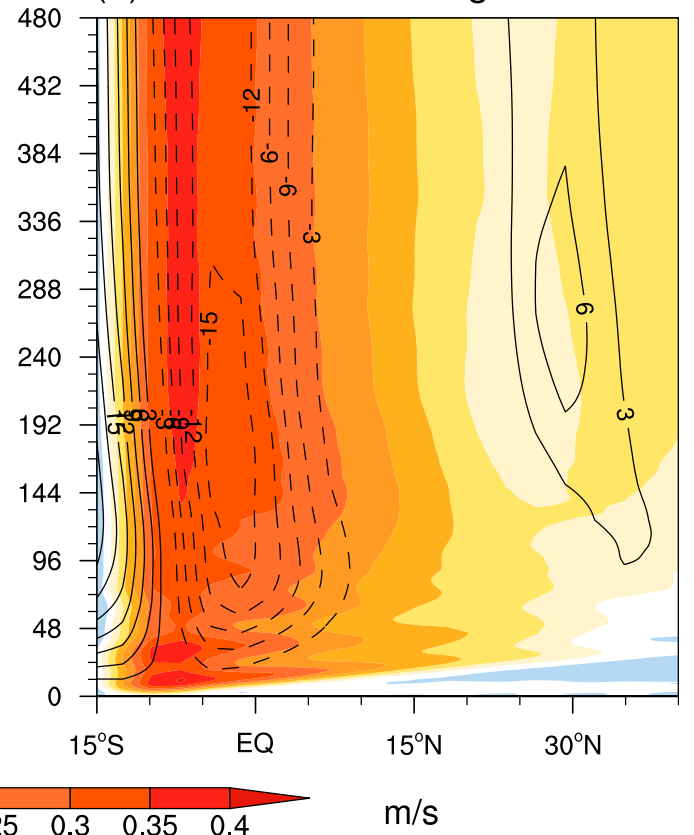

FIG. 12. Time evolutions for the first $480 \mathrm{~h}$ of meridional divergent wind (shading) and vorticity (contours) responses along $130^{\circ} \mathrm{E}$, vertically averaged from 250 to $150 \mathrm{hPa}$ in the LBM experiment with NAUS heating and the JF-mean basic state (a) with and (b) without climatological divergent winds. Contour intervals are $3 \times 10^{-7} \mathrm{~s}^{-1}$ with solid and dashed contours indicating positive and negative responses, respectively, and zero contours omitted. Purple line in (a) indicates a slope of $7 \mathrm{~m} \mathrm{~s}^{-1}$.

efficiency. We argue, however, that the interannual variability of convective activity over NAUS is so strong (Sekizawa et al. 2018) that the remote influence from the AUSM variability can be significantly identified in observations.

Figure 14b suggests that the anomalous convection around the Maritime Continent associated with ENSO has the potential to excite the WP pattern efficiently. As shown in Figs. 4c-d, however, a WP-like signal is not evident in the ENSO-related teleconnection in the JF-mean anomalies. One of the possible reasons may be that ENSO accompanies a zonal dipole of convection anomalies in the tropical Pacific, with the western and eastern centers of action over the Maritime Continent and equatorial central Pacific, respectively, whose remote influences interfere negatively (Son et al. 2014; Jia et al. 2015). In fact, the point-wise forcing experiment (Fig. 14b) suggests that, in association with La Niña, the anomalous heating over the Maritime Continent tends to induce a positive WP response, whereas the anomalous cooling over the equatorial central Pacific tends to drive a negative WP response along with a strong PNA-like pattern. These tendencies have been verified through additional experiments in which the LBM was forced separately by anomalous heating around the Maritime Continent (Fig. 8g) and cooling over the equatorial Pacific (Fig. 8h) as obtained by regressing the JRA-55 diabatic heating anomalies onto the sign-reversed Niño-3.4 index. The responses to the dipole heating and cooling associated with
ENSO thus cancel out mutually, leaving only a weak positive WP-like pattern as the net LBM response shown in Fig. 8i.

\section{Summary and concluding remarks}

With observational datasets, we have investigated the remote influence on the northern extratropics from the interannual AUSM variability. Following Sekizawa et al. (2018), we have detected the AUSM variability as the JF-mean rainfall averaged over nine weather stations in NAUS. Consistent with Sekizawa et al. (2018), the JF-mean AUSM activity is basically a manifestation of internal variability constrained within the monsoon system, with only a weak correlation with ENSO. The associated teleconnection and its mechanisms are illustrated schematically in Fig. 15. The atmospheric circulation anomalies in the Northern extratropics regressed onto the AUSM index resemble the WP pattern, which significantly modulates the East Asian winter monsoon. When the AUSM is stronger than usual, the positive WP-like pattern forms with a cyclonic anomaly east of Japan. This interhemispheric linkage is confirmed in an AGCM experiment without SST forcing, highlighting its robustness. In the observations, the AUSM variability is linearly linked to approximately a quarter of the JF interannual variance of $500-\mathrm{hPa}$ height east of Japan, which is stronger than the corresponding correlation with ENSO. The monsoonal northwesterlies intensify to the west of the cyclonic anomaly, bringing 


\section{JF-mean anomalies of eddy statistics (AUSM)}

(a) $850 \mathrm{hPa}$ v'T' anom. (submonthly)

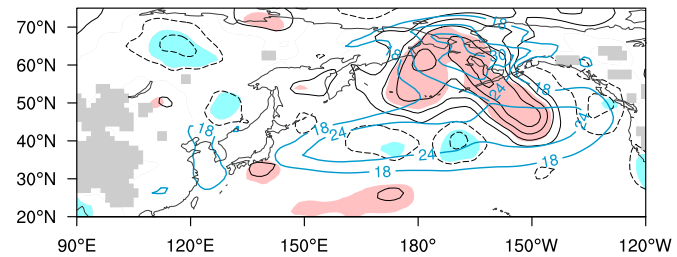

(c) $850 \mathrm{hPa}$ v'T' anom. (transient)

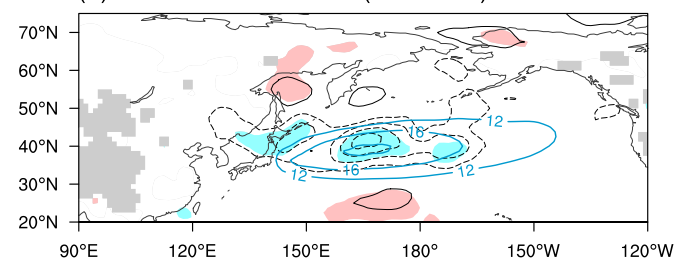

(b) 300hPa v'v' anom. (submonthly)

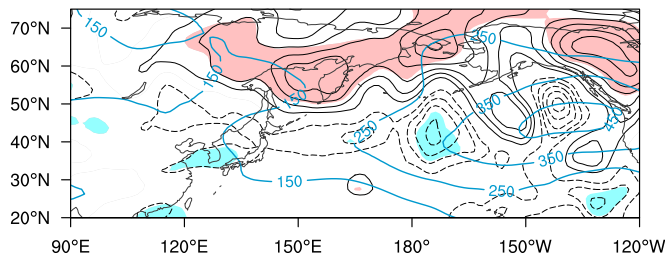

(d) 300hPa v'v' anom. (transient)

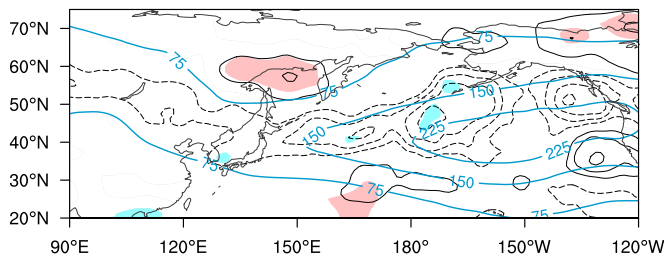

FIG. 13. JF-mean anomalies of (a),(c) 850-hPa meridional eddy heat flux and (b),(d) 300-hPa eddy meridional wind variance (black contours), regressed onto the AUSM index. The eddies are derived from (a),(b) deviation from the JF-mean (1958-2019) and (c),(d) 8-day high-pass filtered fields (1959-2019) based on 6-hourly data of JRA-55. Contour intervals are (a) $0.8 \mathrm{~K} \mathrm{~m} \mathrm{~s}^{-1}$, (b) $5 \mathrm{~m}^{2} \mathrm{~s}^{-2}$, (c) $0.4 \mathrm{~K} \mathrm{~m} \mathrm{~s}^{-1}$, and (d) $3 \mathrm{~m}^{2} \mathrm{~s}^{-2}$, with solid and dashed contours indicated positive and negative anomalies, respectively, and zero contours omitted. Color shading represents the anomalies significant at the $90 \%$ confidence level. Blue contours indicate the corresponding climatology of the eddy statistics.

significant cold anomalies over the Korean Peninsula and western Japan. The enhanced northwesterlies also tend to increase snowfall along the west coast of central Japan, while anomalous descending motions decrease precipitation over southern China and the subtropical North Pacific south of Japan. By contrast, a significant anticyclonic anomaly also forms around the Sea of Okhotsk, accompanying warm anomalies and anomalous onshore winds from the North Pacific to give rise to the reduction of the Okhotsk sea ice extent. Those climate impacts from the AUSM variability are comparable in magnitude to those from ENSO observed in the same region.

Our RWS analyses based on the observational data and LBM experiments have revealed the mechanisms of this teleconnection. In association with anomalously enhanced AUSM convective activity, anomalous northward divergent winds in the upper troposphere cross the equator to reach the prominent subtropical jet over East Asia. The anomalous winds as a modulated local Hadley circulation then generate a pair of anticyclonic and cyclonic sources for quasi-stationary Rossby (a) Heating profile

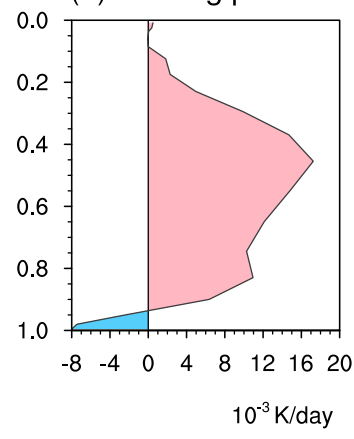

(b) WP-like response to point-wise forcing

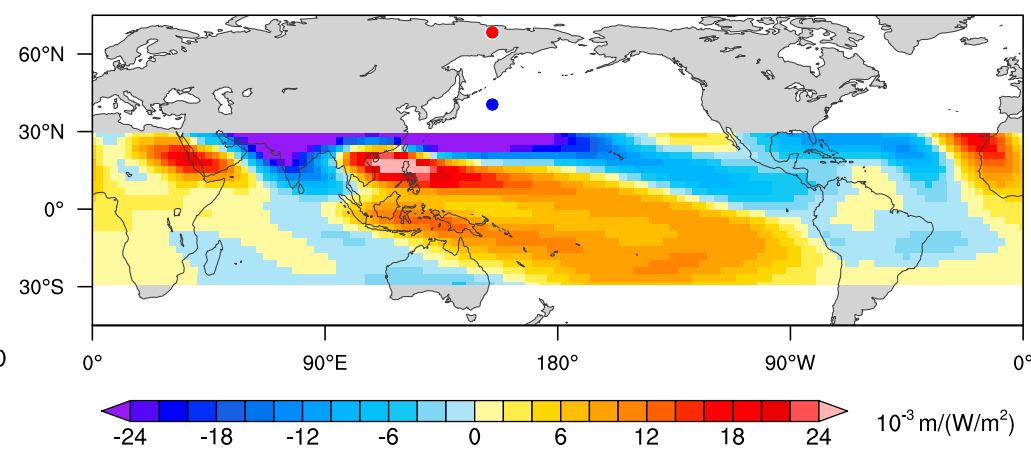

FIG. 14. (a) The vertical profile of the heating rate $\left(10^{-3} \mathrm{~K}_{\text {day }}{ }^{-1}\right)$ imposed for point-wise forcing experiments with the LBM. (b) Differences in $500-\mathrm{hPa}$ geopotential height steady response between $70^{\circ} \mathrm{N}, 155^{\circ} \mathrm{E}$ and $40^{\circ} \mathrm{N}$, $155^{\circ} \mathrm{E}$ (red and blue dots, respectively) plotted as a function of the location of the forcing. The responses are normalized by column-integrated heating rate. A large magnitude at a particular location indicates that the heating placed at that location can efficiently force the WP-like response, while positive and negative values correspond to the positive and negative phases, respectively, of the WP pattern as a response. 


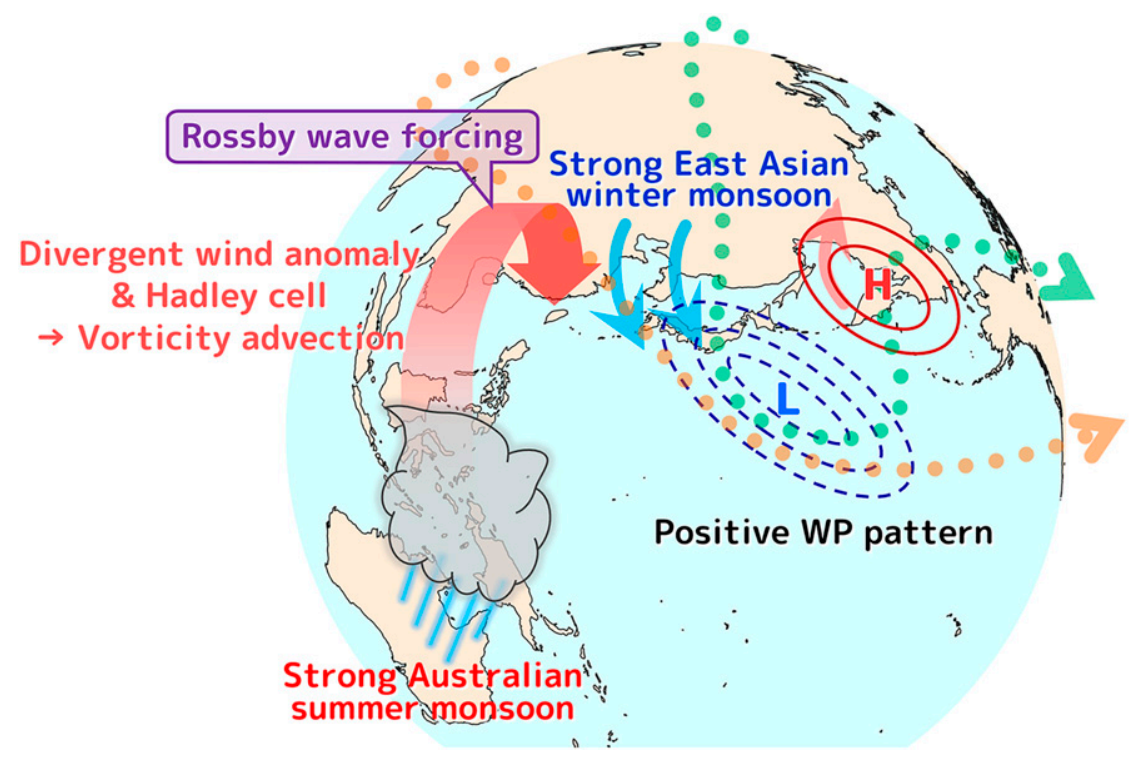

FIG. 15. Schematic of the remote influence of the AUSM variability on East Asia and the western North Pacific. The figure features the phase of the stronger AUSM. See the text for details.

waves. The anomalous upper-level divergent winds also force negative vorticity along the equator, which is further advected northward by the climatological Hadley circulation, amplifying the subtropical anticyclonic vorticity anomaly and downstream wave trains. Anomalous descending motion over East Asia required through quasigeostrophic dynamics may sustain the anomalous divergent wind from NAUS reaching East Asia. The Rossby waves thus forced propagate northeastward and trigger WP-like circulation anomalies, which can amplify through baroclinic energy conversion from the background state (Tanaka et al. 2016). Besides, a set of LBM experiments has revealed additional positive contributions to the WP-like anomalies from anomalous diabatic heating over East Asia and the feedback forcing from modulated activity of submonthly eddies over the North Pacific, both of which can be regarded as secondary responses to the circulation changes induced by the NAUS heating. Meanwhile, Honda et al. (1999) argued that anomalous sea ice extent in the Sea of Okhotsk can modulate the large-scale atmospheric circulation over the North Pacific. Thus, the anomalous sea ice extent due to the AUSM variability may also act to modify the WP-like circulation anomalies.

This study has discussed the influence of the AUSM on the East Asian winter monsoon, but it does not deny the possibility of the reversed influence (i.e., the influence of the East Asian winter monsoon on the AUSM). Indeed, several studies suggested that a cold-air outbreak associated with the intensified monsoonal northerlies from the Asian continent sometimes influences the AUSM activity (e.g., Murakami and Sumi 1982; Zhang and Zhang 2010). In the JF-mean field, however, we cannot find any signature of cold air intrusion into NAUS from the Northern Hemisphere associated with the strong AUSM. In this context, we may consider the present study to have revealed part of the possible intermonsoon interaction within the complex Asian-Australian monsoon system.
As found by Cai et al. (2010), the relationship between ENSO and Australian summer rainfall has undergone multidecadal modulations in accordance with the interdecadal Pacific oscillation, superposed on a long-term increasing trend in the summer rainfall. These long-term changes may affect not only the local NAUS climate but also the wintertime East Asian climate through the teleconnection shown in the present study. Moreover, long-term modulations and trends in the atmospheric circulation over the western North Pacific may affect the teleconnection. These issues are left for our future studies.

The present study suggests that understanding of the AUSM is important not only for the Australian climate but also for the understanding of climate variability in East Asia and the western North Pacific. While the dominance of atmospheric internal variability in AUSM interannual variability indicates limited seasonal predictability, forecasts with shorter lead times (subseasonal forecasts) may find some predictability (Marshall and Hendon 2015). We expect that improvement in the reproducibility and prediction skill of the AUSM variability in climate models can remotely contribute to improving those for East Asia and the western North Pacific. Besides, any biases in the teleconnection structure, as seen in our AGCM experiment, also affects predictability. Investigation on reproducibility of the remote influence in a multimodel framework would provide some implications for subseasonalto-seasonal prediction of wintertime climate in East Asia and the western North Pacific.

Acknowledgments. This work is supported by the Japanese Ministry of Education, Culture, Sports, Science and Technology through the Arctic Challenge for Sustainability (ArCS) II Program (JPMXD1420318865), by Japan Society for the Promotion of Science through Grants-in-Aid for Scientific Research JP18H01278, JP18H01281, JP19H01964, JP19H05702, 
JP19H05703, and JP20H01970, by the Japan Science and Technology Agency through COI-NEXT (JPMJPF2013), and by the Environmental Restoration and Conservation Agency of Japan through the Environmental Research and Technology Development Fund (JPMEERF20192004). The authors acknowledge constructive comments on SS's doctoral dissertation, a part of which is the present paper, by Profs. Y. Masumoto, Y. N. Takayabu, M. Watanabe, and H. Miura (University of Tokyo). Discussions with Profs. B. Taguchi (University of Toyama), K. Nishii (Mie University) and Dr. M. Mori (Kyushu University) have been helpful in carrying out this research. The authors also thank Dr. H. Hendon (Bureau of Meteorology), Prof. M. Reeder (Monash University), and their colleagues for useful discussions and allowing to access some local data. Valuable comments by three anonymous reviewers have helped the authors to improve the manuscript.

Data availability statement. Australian rainfall datasets are obtained from the Australian Bureau of Meteorology (http:// www.bom.gov.au/climate/data-services/). The JRA-55 datasets are provided by the Japan Meteorological Agency (https:// jra.kishou.go.jp/JRA-55/index_en.html), HadISST data by Met Office Hadley Centre (https://www.metoffice.gov.uk/hadobs/ hadisst/), and OISST sea-ice concentration data by the NOAA/OAR/ESRL PSD (https://psl.noaa.gov/). APHRODITE datasets are obtained from their website at http://aphrodite.st.hirosakiu.ac.jp and GlobSnow data at https://www.globsnow.info/. Documents and codes for the LBM can be available through https://ccsr.aori.u-tokyo.ac.jp/ lbm/sub/lbm.html. NCAR Command Language (https://doi.org/10.5065/D6WD3XH5) version 6.5.0 has been used for the analyses and visualizations.

\section{REFERENCES}

Alexander, M. A., I. Bladé, M. Newman, J. R. Lanzante, N.-C. Lau, and J. D. Scott, 2002: The atmospheric bridge: The influence of ENSO teleconnections on air-sea interaction over the global oceans. J. Climate, 15, 2205-2231, https://doi.org/10.1175/15200442(2002)015<2205:TABTIO >2.0.CO;2.

Anderson, J. L., and Coauthors, 2005: The new GFDL global atmosphere and land model AM2-LM2: Evaluation with prescribed SST simulations. J. Climate, 17, 4641-4673, https:// doi.org/10.1175/JCLI-3223.1.

Cai, W., P. van Rensch, T. Cowan, and A. Sullivan, 2010: Asymmetry in ENSO teleconnection with regional rainfall, its multidecadal variability, and impact. J. Climate, 23, 49444955, https://doi.org/10.1175/2010JCLI3501.1.

,,,--- and H. H. Hendon, 2011: Teleconnection pathways of ENSO and the IOD and the mechanisms for impacts on Australian rainfall. J. Climate, 24, 3910-3923, https:// doi.org/10.1175/2011JCLI4129.1.

Drosdowsky, W., 1996: Variability of the Australian summer monsoon at Darwin: 1957-1992. J. Climate, 9, 85-96, https://doi.org/ 10.1175/1520-0442(1996)009<0085:VOTASM > 2.0.CO;2.

—_, and M. Williams, 1991: The Southern Oscillation in the Australian region. Part I: Anomalies at the extremes of the oscillation. J. Climate, 4, 619-638, https://doi.org/10.1175/ 1520-0442(1991)004<0619:TSOITA > 2.0.CO;2.

Evans, S., R. Marchand, and T. Ackerman, 2014: Variability of the Australian monsoon and precipitation trends at Darwin. J. Climate, 27, 8487-8500, https://doi.org/10.1175/JCLI-D-13-00422.1.
Gill, A. E., 1980: Some simple solutions for heat-induced tropical circulation. Quart. J. Roy. Meteor. Soc., 106, 447-462, https:// doi.org/10.1002/qj.49710644905.

Hanawa, K., T. Watanabe, N. Iwasaka, T. Suga, and Y. Toba, 1988: Surface thermal conditions in the western North Pacific during the ENSO events. J. Meteor. Soc. Japan, 66, 445-456, https:// doi.org/10.2151/jmsj1965.66.3_445.

Held, I. M., and A. Y. Hou, 1980: Nonlinear axially symmetric circulations in a nearly inviscid atmosphere. J. Atmos. Sci., 37, 515-533, https://doi.org/10.1175/1520-0469(1980)037<0515: NASCIA $>2.0 . \mathrm{CO} ; 2$.

Hendon, H. H., and B. Liebmann, 1990a: A composite study of onset of the Australian summer monsoon. J. Atmos. Sci., 47, 2227-2240, https://doi.org/10.1175/1520-0469(1990)047<2227: ACSOOO $>2.0 . \mathrm{CO} ; 2$.

—_, and —_, 1990b: The intraseasonal (30-50 day) oscillation of the Australian summer monsoon. J. Atmos. Sci., 47, 2909-2924, https://doi.org/10.1175/1520-0469(1990) 047<2909:TIDOOT > 2.0.CO;2.

, E.-P. Lim, and G. Liu, 2012: The role of air-sea interaction for prediction of Australian summer monsoon rainfall. J. Climate, 25, 1278-1290, https://doi.org/10.1175/JCLI-D-11-00125.1.

Hoerling, M. P., and A. Kumar, 2002: Atmospheric response patterns associated with tropical forcing. J. Climate, $\mathbf{1 5}$, 2184-2203, https://doi.org/10.1175/1520-0442(2002)015<2184: ARPAWT>2.0.CO;2.

Holland, G. J., 1986: Interannual variability of the Australian summer monsoon at Darwin: 1952-82. Mon. Wea. Rev., 114, 594-604, https://doi.org/10.1175/1520-0493(1986)114<0594: IVOTAS $>2.0 . \mathrm{CO} ; 2$.

Honda, M., K. Yamazaki, H. Nakamura, and K. Takeuchi, 1999: Dynamic and thermodynamic characteristics of atmospheric response to anomalous sea-ice extent in the Sea of Okhotsk. J. Climate, 12, 3347-3358, https://doi.org/ 10.1175/1520-0442(1999)012<3347:DATCOA>2.0.CO;2.

Horel, J. D., and J. M. Wallace, 1981: Planetary-scale atmospheric phenomena associated with the Southern Oscillation. Mon. Wea. Rev., 109, 813-829, https://doi.org/10.1175/1520-0493(1981) 109<0813:PSAPAW>2.0.CO;2.

Hoskins, B. J., and D. J. Karoly, 1981: The steady linear response of a spherical atmosphere to thermal and orographic forcing. J. Atmos. Sci., 38, 1179-1196, https://doi.org/10.1175/15200469(1981)038<1179:TSLROA $>2.0$.CO;2.

_ , and G.-Y. Yang, 2021: The detailed dynamics of the Hadley cell. Part II: December-February. J. Climate, 34, 805-823, https://doi.org/10.1175/JCLI-D-20-0504.1.

Jia, X., S. Wang, H. Lin, and Q. Bao, 2015: A connection between the tropical Pacific Ocean and the winter climate in the AsianPacific region. J. Geophys. Res., 120, 430-448, https://doi.org/ 10.1002/2014JD022324.

Jones, D., W. Wang, and R. Fawcett, 2009: High-quality spatial climate data-sets for Australia. Aust. Meteor. Oceanogr. J., 58, 233-248, https://doi.org/10.22499/2.5804.003.

Kajikawa, Y., B. Wang, and J. Yang, 2010: A multi-time scale Australian monsoon index. Int. J. Climatol., 30, 1114-1120, https://doi.org/10.1002/joc.1955.

Kobayashi, S., and Coauthors, 2015: The JRA-55 Reanalysis: General specifications and basic characteristics. J. Meteor. Soc. Japan, 93, 5-48, https://doi.org/10.2151/jmsj.2015-001.

Kumar, A., M. Chen, and W. Wang, 2013: Understanding prediction skill of seasonal mean precipitation over the tropics. J. Climate, 26, 5674-5681, https://doi.org/10.1175/JCLI-D-1200731.1. 
Larkin, N. K., and D. E. Harrison, 2002: ENSO warm (El Niño) and cold (La Niña) event life cycles: Ocean surface anomaly patterns, their symmetries, asymmetries, and implications. J. Climate, 15, 1118-1140, https://doi.org/10.1175/ 1520-0442(2002)015<1118:EWENOA > 2.0.CO;2.

Lau, N.-C., 1988: Variability of the observed midlatitude storm tracks in relation to low frequency changes in the circulation pattern. J. Atmos. Sci., 45, 2718-2743, https://doi.org/10.1175/ 1520-0469(1988)045<2718:VOTOMS > 2.0.CO;2.

—, and M. J. Nath, 1991: Variability of the baroclinic and barotropic transient eddy forcing associated with monthly changes in the midlatitude storm tracks. J. Atmos. Sci., 48, 2589-2613, https://doi.org/10.1175/1520-0469(1991)048<2589:VOTBAB > 2.0.CO;2.

Lo, F., M. C. Wheeler, H. Meinke, and A. Donald, 2007: Probabilistic forecasts of the onset of the north Australian wet season. Mon. Wea. Rev., 135, 3506-3520, https://doi.org/ 10.1175/MWR3473.1.

Marshall, A. G., and H. H. Hendon, 2015: Subseasonal prediction of Australian summer monsoon anomalies. Geophys. Res. Lett., 42, 10 913-10 919, https://doi.org/10.1002/2015GL067086.

Matsuno, T., 1966: Quasi-geostrophic motions in the equatorial area. J. Meteor. Soc. Japan, 44, 25-43, https://doi.org/10.2151/ jmsj1965.44.1_25.

Murakami, T., and A. Sumi, 1982: Southern Hemisphere summer monsoon circulation during the 1978-79 WMONEX. Part II: Onset, active and break monsoons. J. Meteor. Soc. Japan, 60, 649-671, https://doi.org/10.2151/jmsj1965.60.2_649.

Qin, J., and W. A. Robinson, 1993: On the Rossby wave source and the steady linear response to tropical forcing. J. Atmos. Sci., 50, 1819-1823, https://doi.org/10.1175/1520-0469(1993) $050<1819$ :OTRWSA $>2.0 . \mathrm{CO} ; 2$.

Rayner, N. A., D. E. Parker, E. B. Horton, C. K. Folland, L. V. Alexander, D. P. Rowell, E. C. Kent, and A. Kaplan, 2003: Global analyses of sea surface temperature, sea ice, and night marine air temperature since the late nineteenth century. J. Geophys. Res., 108, 4407, https://doi.org/10.1029/ 2002JD002670.

Reynolds, R. W., N. A. Rayner, T. M. Smith, D. C. Stokes, and W. Wang, 2002: An improved in situ and satellite SST analysis for climate. J. Climate, 15, 1609-1625, https://doi.org/10.1175/ 1520-0442(2002)015<1609:AIISAS > 2.0.CO;2.

—, T. M. Smith, C. Liu, D. B. Chelton, K. S. Casey, and M. G. Schlax, 2007: Daily high-resolution-blended analysis for sea surface temperatures. J. Climate, 20, 5473-5496, https://doi.org/ 10.1175/2007JCLI1824.1.

Risbey, J. S., M. J. Pook, P. C. McIntosh, M. C. Wheeler, and H. H. Hendon, 2009: On the remote drivers of rainfall variability in Australia. Mon. Wea. Rev., 137, 3233-3253, https://doi.org/ 10.1175/2009MWR2861.1.

Saji, N. H., B. N. Goswami, P. N. Vinayachandran, and T. Yamagata, 1999: A dipole in the tropical Indian Ocean. Nature, 401, 360363, https://doi.org/10.1038/43854.

Sakai, K., and R. Kawamura, 2009: Remote response of the East Asian winter monsoon to tropical forcing related to El NiñoSouthern Oscillation. J. Geophys. Res., 114, D06105, https:// doi.org/10.1029/2008JD010824.

Sardeshmukh, P. D., and B. J. Hoskins, 1988: The generation of global rotational flow by steady idealized tropical divergence. J. Atmos. Sci., 45, 1228-1251, https://doi.org/10.1175/15200469(1988)045<1228:TGOGRF>2.0.CO;2.

Sekizawa, S., H. Nakamura, and Y. Kosaka, 2018: Interannual variability of the Australian summer monsoon system internally sustained through wind-evaporation feedback. Geophys. Res. Lett., 45, 7748-7755, https://doi.org/10.1029/2018GL078536.

Shiozaki, M., T. Enomoto, and K. Takaya, 2021: Disparate midlatitude responses to the eastern Pacific El Niño. J. Climate, 34, 773-786, https://doi.org/10.1175/JCLI-D-20-0246.1.

Son, H.-Y., J.-Y. Park, J.-S. Kug, J. Yoo, and C.-H. Kim, 2014: Winter precipitation variability over Korean Peninsula associated with ENSO. Climate Dyn., 42, 3171-3186, https:// doi.org/10.1007/s00382-013-2008-1.

Takala, M., K. Luojus, J. Pulliainen, C. Derksen, J. Lemmetyinen, J.-P. Kärnä, J. Koskinen, and B. Bojkov, 2011: Estimating Northern Hemisphere snow water equivalent for climate research through assimilation of spaceborne radiometer data and ground-based measurements. Remote Sens. Environ., 115, 3517-3529, https://doi.org/10.1016/j.rse.2011.08.014.

Takaya, K., and H. Nakamura, 2001: A formulation of a phaseindependent wave-activity flux for stationary and migratory quasigeostrophic eddies on a zonally varying basic flow. J. Atmos. Sci., 58, 608-627, https://doi.org/10.1175/15200469(2001)058<0608:AFOAPI > 2.0.CO;2.

$\longrightarrow$, and —, 2013: Interannual variability of the East Asian winter monsoon and related modulations of the planetary waves. J. Climate, 26, 9445-9461, https://doi.org/10.1175/JCLID-12-00842.1.

Tanaka, S., K. Nishii, and H. Nakamura, 2016: Vertical structure and energetics of the western Pacific teleconnection pattern. J. Climate, 29, 6597-6616, https://doi.org/10.1175/JCLI-D-150549.1.

Trenberth, K. E., and D. J. Shea, 2005: Relationships between precipitation and surface temperature. Geophys. Res. Lett., 32, L14703, https://doi.org/10.1029/2005GL022760.

—, G. W. Branstator, D. Karoly, A. Kumar, N.-C. Lau, and C. Ropelewski, 1998: Progress during TOGA in understanding and modeling global teleconnections associated with tropical sea surface temperatures. J. Geophys. Res., 103, 14 291-14 324, https://doi.org/10.1029/97JC01444.

Ueda, H., A. Kibe, M. Saitoh, and T. Inoue, 2015: Snowfall variations in Japan and its linkage with tropical forcing. Int. J. Climatol., 35, 991-998, https://doi.org/10.1002/joc.4032.

Wallace, J. M., and D. S. Gutzler, 1981: Teleconnections in the geopotential height field during the Northern Hemisphere winter. Mon. Wea. Rev., 109, 784-812, https://doi.org/10.1175/ 1520-0493(1981)109<0784:TITGHF>2.0.CO;2.

Wang, B., R. Wu, and X. Fu, 2000: Pacific-East Asian teleconnection: How does ENSO affect East Asian climate? J. Climate, 13, 1517-1536, https://doi.org/10.1175/1520-0442(2000) $013<1517$ :PEATHD $>2.0$. CO 2 .

Watanabe, M., and M. Kimoto, 2000: Atmosphere-ocean thermal coupling in the North Atlantic: A positive feedback. Quart. J. Roy. Meteor. Soc., 126, 3343-3369, https://doi.org/10.1002/ qj.49712657017.

Wheeler, M. C., H. H. Hendon, S. Cleland, H. Meinke, and A. Donald, 2009: Impacts of the Madden-Julian oscillation on Australian rainfall and circulation. J. Climate, 22, 1482-1498, https://doi.org/10.1175/2008JCLI2595.1.

Wu, R., and B. P. Kirtman, 2007: Regimes of seasonal air-sea interaction and implications for performance of forced simulations. Climate Dyn., 29, 393-410, https://doi.org/10.1007/ s00382-007-0246-9.

Yasutomi, N., A. Hamada, and A. Yatagai, 2011: Development of a long-term daily gridded temperature dataset and its application to rain/snow discrimination of daily precipitation. Global Environ. Res., 15, 165-172. 
Yatagai, A., K. Kamiguchi, O. Arakawa, A. Hamada, N. Yasutomi, and A. Kitoh, 2012: APHRODITE: Constructing a long-term daily gridded precipitation dataset for Asia based on a dense network of rain gauges. Bull. Amer. Meteor. Soc., 93, 14011415, https://doi.org/10.1175/BAMS-D-11-00122.1.

Zhang, C., and H. Zhang, 2010: Potential impacts of East Asian winter monsoon on climate variability and predictability in the Australian summer monsoon region. Theor. Appl. Climatol., 101, 161-177, https://doi.org/10.1007/s00704-009-0246-2.

Zheng, X., H. Nakamura, and J. A. Renwick, 2000: Potential predictability of seasonal means based on monthly time series of meteorological variables. J. Climate, 13, 25912604, https://doi.org/10.1175/1520-0442(2000)013<2591: PPOSMB $>2.0 . \mathrm{CO} ; 2$.

Zhu, Z., 2018: Breakdown of the relationship between Australian summer rainfall and ENSO caused by tropical Indian Ocean SST warming. J. Climate, 31, 2321-2336, https://doi.org/10.1175/ JCLI-D-17-0132.1.

Zwiers, F. W., 1996: Interannual variability and predictability in an ensemble of AMIP climate simulations conducted with the CCC GCM2. Climate Dyn., 12, 825-847, https://doi.org/10.1007/ s003820050146. 